\title{
Optimization of Manganese Recovery from a Solution Based on Lithium-Ion Batteries by Solvent Extraction with D2EHPA
}

\author{
Nathália Vieceli ${ }^{1, *}$, Niclas Reinhardt ${ }^{2}$, Christian Ekberg $^{1}$ and Martina Petranikova ${ }^{1}$ \\ 1 Department of Chemistry and Chemical Engineering, Industrial Materials Recycling and Nuclear Chemistry, \\ Chalmers University of Technology, SE-41296 Gothenburg, Sweden; che@chalmers.se (C.E.); \\ martina.petranikova@chalmers.se (M.P.) \\ 2 MEAB Metallextraktion AB, Datavägen 51, S-43632 Askim, Sweden; niclas@meab-mx.se \\ * Correspondence: nathalia.vieceli@chalmers.se
}

check for

updates

Citation: Vieceli, N.; Reinhardt, N.; Ekberg, C.; Petranikova, M. Optimization of Manganese Recovery from a

Solution Based on Lithium-Ion Batteries by Solvent Extraction with D2EHPA. Metals 2021, 11, 54 https://doi.org/10.3390/met110 10054

Received: 1 December 2020 Accepted: 24 December 2020 Published: 29 December 2020

Publisher's Note: MDPI stays neutral with regard to jurisdictional clai$\mathrm{ms}$ in published maps and institutional affiliations.

Copyright: (C) 2020 by the authors. Licensee MDPI, Basel, Switzerland. This article is an open access article distributed under the terms and conditions of the Creative Commons Attribution (CC BY) license (https:// creativecommons.org/licenses/by/ $4.0 /)$.

\begin{abstract}
Manganese is a critical metal for the steelmaking industry, and it is expected that its world demand will be increasingly affected by the growing market of lithium-ion batteries. In addition to the increasing importance of manganese, its recycling is mainly determined by trends in the recycling of iron and steel. The recovery of manganese by solvent extraction has been widely investigated; however, the interaction of different variables affecting the process is generally not assessed. In this study, the solvent extraction of manganese from a solution based on lithium-ion batteries was modeled and optimized using factorial designs of experiments and the response surface methodology. Under optimized conditions (O:A of 1.25:1, pH 3.25, and 0.5 M bis(2-ethylhexyl) phosphoric acid (D2EHPA)), extractions above 70\% Mn were reached in a single extraction stage with a coextraction of less than $5 \% \mathrm{Co}$, which was mostly removed in two scrubbing stages. A stripping product containing around $23 \mathrm{~g} / \mathrm{L} \mathrm{Mn}$ and around $0.3 \mathrm{~g} / \mathrm{L}$ Co can be obtained under optimized conditions (O:A of 8:1, $1 \mathrm{M} \mathrm{H}_{2} \mathrm{SO}_{4}$ and around $13 \mathrm{~min}$ of contact time) in one stripping stage.
\end{abstract}

Keywords: lithium-ion battery; battery recycling; manganese recovery; solvent extraction; D2EHPA; factorial design of experiments

\section{Introduction}

Manganese is one of the most abundant metals in the Earth's crust; however, manganese is highly dispersed (low-grade), and minerals are widely distributed. The identified manganese resources are concentrated in a few countries-the main manganese mining areas are in China, South Africa, Australia, and Gabon [1-3].

The main end use of manganese is in the steel industry, which accounts for $90 \%$ of the world's manganese demand. Manganese is also widely used in ironmaking and alloys with aluminum, magnesium, and copper [3-6]. Non-metallurgical applications account for only $5-10 \%$ of the manganese consumption, which is used in electrical systems, in the chemical industry, in the ceramic and glass production, and in the agricultural sector [7]. In electrical systems, manganese dioxide is used for cathodic depolarizer in dry cells, alkaline batteries, and lithium-ion batteries (LIBs) [4].

Natural manganese dioxide is used in dry cells, while high-grade synthetic manganese dioxide is produced chemically or by electrolysis to be used in alkaline batteries and LIBs [4]. Lithium manganese spinels (such as $\mathrm{LiMn}_{2} \mathrm{O}_{4}$ ) and layered lithium-nickel-manganesecobalt (NMC) oxide systems have an important role in the development of advanced rechargeable lithium-ion batteries, with cost and environmental advantages [8]. Thus, nowadays, most automakers and some electronics makers use some version of NMC system in their LIBs [9].

In this context, the United States of America Department of Defense has recently classified manganese as one of the most critical mineral commodities for the United States because it is essential for important industrial sectors, has no substitutes, and has a 
potential for supply disruptions, since the country is strongly dependent on imports [10]. Additionally, the United States included electrolytic manganese metal in the National Defense Stockpile in 2019 as a critical material for defense purposes [2].

Although it is expected that steel will continue leading the manganese demand, the consumption of manganese in batteries applications is projected to grow fast in the next decade, boosted by the rapid growth in the lithium-ion battery market, which is expected to increase from $\$ 35$ billion USD in 2020 and reach $\$ 71$ billion USD in 2025 [11,12]. Thus, electrolytic manganese dioxide (EMD) for the battery industry is expected to be the fastestgrowing segment of the manganese market [13], increasing the manganese production along with the global demand for batteries [14].

EMD is generally produced from high-grade manganese ores [15], and in general, converting manganese ores to EMD involves a high-temperature pyrometallurgical process, which has some drawbacks such as environmental impacts, high-energy consumption, and high costs. Furthermore, because the roasting process decreases the oxide content in the ore, EMD producers face competition from chemical and steel industry buyers of high-grade manganese ores [16]. In this context, the recovery of manganese from spent LIBs can help decrease supply risks and impacts linked to the primary production of manganese. However, although there is an increasing importance of manganese, its recycling is mainly determined by trends in the recycling of iron and steel, and in general, materials are not recycled specifically due to their manganese content $[2,17,18]$. Moreover, when it comes to LIBs recycling, the presence of manganese in the leaching solutions has been linked to a decrease in the selective separation of cobalt and nickel, and for this reason, manganese should be previously recovered $[19,20]$.

The recovery of manganese from primary and secondary resources by solvent extraction has been investigated by several authors [14,20-26]. Table 1 (on the next page) summarizes the optimal extraction conditions described in some studies focused on the extraction of manganese from different feed solutions, including from leach solutions from spent LIBs. It is possible to highlight that bis(2-ethylhexyl) phosphoric acid (D2HEPA) is the most widely used extractant to recover Mn from liquors from LIBs as well as from other solutions.

Although several studies on the recovery of manganese by solvent extraction have been published, the effect of different variables affecting the process is generally approached using one-factor-at-a-time, which does not allow identifying interaction effects among them. In this context, the main goal of this study was to optimize the solvent extraction of manganese using the factorial design of experiments and response surface methodologies to assess and model the effects of the variables affecting the process. The optimization of the recovery of manganese was studied using a synthetic solution based on an acid leach from spent LIBs. The results can support further investigations focused on the recovery of manganese from spent LIBs, which can be considered an important secondary resource of a critical material for many important industrial sectors. 
Table 1. Summary of conditions for the manganese solvent extraction from published studies (corresponding to the best conditions reported).

\begin{tabular}{|c|c|c|c|c|c|c|c|c|c|c|c|c|c|}
\hline \multirow{2}{*}{ Extractant } & \multirow{2}{*}{ Saponification } & \multirow{2}{*}{ Modifier } & \multirow{2}{*}{ O:A } & \multirow{2}{*}{$\begin{array}{l}\text { Optimum } \\
\text { pH }\end{array}$} & \multirow{2}{*}{$\begin{array}{c}\text { Temperature } \\
\left({ }^{\circ} \mathrm{C}\right)\end{array}$} & \multirow{2}{*}{$\begin{array}{c}\text { Contact } \\
\text { Time (min) }\end{array}$} & \multirow{2}{*}{ Feed } & \multicolumn{4}{|c|}{ Initial Composition (g/L) } & \multirow{2}{*}{$\%$ E (Mn) } & \multirow{2}{*}{ Reference } \\
\hline & & & & & & & & Mn & Co & $\mathrm{Ni}$ & $\mathbf{L i}$ & & \\
\hline 0.4 M D2EHPA & - & - & $2: 1$ & 3.2 & 25 & 15 & $\begin{array}{l}\text { Leach solution } \\
\text { produced from } \\
\text { spent LIBs (acid } \\
\text { leaching with } \\
\mathrm{H}_{2} \mathrm{SO}_{4} \text { and } \mathrm{H}_{2} \mathrm{O}_{2} \text { ) }\end{array}$ & 3.66 & 19.33 & 5.19 & 3.58 & - & {$[20]$} \\
\hline $15 \%$ D2EHPA & $\begin{array}{l}60 \% \text { (with } 0.5 \\
\mathrm{M} \text { ammonia) }\end{array}$ & $5 \%$ TBP & $1: 1$ & 2.25 & 25 & 5 & $\begin{array}{l}\text { Leaching liquor of } \\
\text { spent LIBs }\end{array}$ & 5.91 & 24.79 & 6.24 & 6.68 & 99.9 & [26] \\
\hline $\begin{array}{c}4 \mathrm{M} \\
\text { (D2EHPA/Mn } \\
\text { molar) }\end{array}$ & $\begin{array}{l}\text { 65\% (with } \\
\mathrm{NaOH} 5 \mathrm{M})\end{array}$ & $10 \%$ ТВP & $1: 1$ & 3.8 & room & 10 & $\begin{array}{c}\text { Electrodic LIB } \\
\text { powder pre-leached } \\
\text { with } \mathrm{H}_{2} \mathrm{SO}_{4}\end{array}$ & 4.6 & 21.8 & 2.7 & 3.2 & $\sim 90$ & [25] \\
\hline $\begin{array}{c}0.05 \mathrm{M} \\
\text { NaD2EHPA } \\
\text { (best results) }\end{array}$ & - & $5 \%$ TBP & $9: 8$ & 2.7 & 30 & 5 & $\begin{array}{l}\text { Stock solution with } \\
\text { Mn and Co }(0.01 \mathrm{M})\end{array}$ & $0.01 \mathrm{M}$ & $0.01 \mathrm{M}$ & - & - & $99.94 \%$ & [27] \\
\hline $\begin{array}{c}\text { 15\% Cobalt } \\
\text { loaded D2EHPA }\end{array}$ & $\begin{array}{l}70-75 \% \text { (with } \\
\mathrm{NaOH} 10 \mathrm{M})\end{array}$ & $5 \%$ TBP & $1: 1$ & 3.2 & 25 & 5 & $\begin{array}{l}\text { Sulfuric acid } \\
\text { leaching liquor of } \\
\text { mixed types of } \\
\text { cathode materials } \\
\text { (real sample) waste } \\
\text { cathode materials }\end{array}$ & 6.31 & 6.45 & 6.89 & 1.6 & $99 \%$ & [24] \\
\hline $\begin{array}{c}20 \% \\
\text { PC } 88 \mathrm{~A} / 25 \% \\
\text { Versatic } 10 \\
\end{array}$ & - & - & $1: 1$ & 4.5 & room & 5 & $\begin{array}{l}\text { Leaching solution } \\
\text { from spent LIBs }\end{array}$ & 11.7 & 11.4 & 12.2 & 5.3 & $99.5 \%$ & [23] \\
\hline $\begin{array}{c}25 \% \text { Cobalt } \\
\text { loaded D2EHPA }\end{array}$ & - & 1-decanol & $1: 1$ & 3.5 & 25 & 5 & $\begin{array}{l}\text { Cobalt electrolyte } \\
\text { solution }\end{array}$ & 0.8 & 55.7 & - & - & $\begin{array}{c}100 \%(70 \% \\
\text { in one stage) }\end{array}$ & [28] \\
\hline 10\% D2EHPA & - & $5 \%$ ТВР & $1: 1$ & 3.5 & 40 & 10 & $\begin{array}{c}\text { Synthetic laterite } \\
\text { solution containing } \\
\mathrm{Ni}, \mathrm{Co}, \mathrm{Mn}, \mathrm{Mg}, \mathrm{Zn} \text {, } \\
\text { and } \mathrm{Cu}\end{array}$ & 2 & 0.3 & 3 & - & $99 \%$ & [29] \\
\hline
\end{tabular}


Table 1. Cont.

\begin{tabular}{|c|c|c|c|c|c|c|c|c|c|c|c|c|c|}
\hline \multirow{2}{*}{ Extractant } & \multirow{2}{*}{ Saponification } & \multirow{2}{*}{ Modifier } & \multirow{2}{*}{ O:A } & \multirow{2}{*}{$\begin{array}{c}\text { Optimum } \\
\text { pH }\end{array}$} & \multirow{2}{*}{$\begin{array}{c}\text { Temperature } \\
\left({ }^{\circ} \mathrm{C}\right)\end{array}$} & \multirow{2}{*}{$\begin{array}{c}\text { Contact } \\
\text { Time (min) }\end{array}$} & \multirow{2}{*}{ Feed } & \multicolumn{4}{|c|}{ Initial Composition (g/L) } & \multirow{2}{*}{$\% \mathrm{E}(\mathrm{Mn})$} & \multirow{2}{*}{ Reference } \\
\hline & & & & & & & & Mn & Co & $\mathrm{Ni}$ & $\mathbf{L i}$ & & \\
\hline $30 \%$ D2EHPA & $\begin{array}{c}20 \% \text { (with } \\
\mathrm{NaOH} 10 \mathrm{M})\end{array}$ & $5 \%$ TBP & $1: 1$ & $2.6-2.7$ & room & 15 & $\begin{array}{l}\text { Leaching solution } \\
\text { from spent } \mathrm{LIBs,} \\
\text { treated with } \mathrm{H}_{2} \mathrm{SO}_{4} \\
\text { and } \mathrm{H}_{2} \mathrm{O}_{2}\end{array}$ & 2 & 0.3 & 3 & - & $\begin{array}{l}\text { Removal of } \\
\mathrm{Mn} \text { and } \mathrm{Cu}\end{array}$ & [22] \\
\hline $40 \%$ D2EHPA & - & - & $1: 1$ & 3.5 & room & 10 & $\begin{array}{l}\text { Leaching acid } \\
\text { solution from } \\
\text { cathode material }\end{array}$ & 9.18 & 11.32 & 11.51 & 1.76 & $\sim 100$ & [21] \\
\hline 0.4 M D2EHPA & - & - & $2: 1$ & 3.2 & 25 & 15 & $\begin{array}{l}\text { Leach solution } \\
\text { produced from } \\
\text { spent LIBs (acid } \\
\text { leaching with } \\
\mathrm{H}_{2} \mathrm{SO}_{4} \text { and } \mathrm{H}_{2} \mathrm{O}_{2} \text { ) }\end{array}$ & 3.66 & 19.33 & 5.19 & 3.58 & - & [20] \\
\hline $\begin{array}{c}\text { 20\% D2EHPA } \\
\quad(0.6 \mathrm{M})\end{array}$ & $\begin{array}{l}\text { 70-75\% (with } \\
\mathrm{NaOH} 10 \mathrm{M} \text { ) }\end{array}$ & - & $1: 2$ & $4-5$ & 25 & 5 & $\begin{array}{l}\mathrm{Co}, \mathrm{Ni} \text {, and } \mathrm{Li} \text { were } \\
\text { removed by } \\
\text { precipitation }\end{array}$ & 5.27 & 5.84 & 4.93 & 1.25 & $97 \%$ & {$[30]$} \\
\hline $\begin{array}{c}\text { 25\% D2EHPA } \\
\text { (Cyanex } 272 \\
\text { was also tested) }\end{array}$ & - & - & $1: 1.5$ & 2.7 & 5 and 25 & n.i. & $\begin{array}{l}\text { Synthetic sulfuric } \\
\text { acid solutions }(\mathrm{Ca} \text {, } \\
\mathrm{Mn}, \mathrm{Na} \text {, and } \mathrm{Mg})\end{array}$ & $0.58-5.3$ & - & - & - & $65 \%$ & [32] \\
\hline D2EHPA & - & - & $\begin{array}{l}1: 1- \\
1: 5\end{array}$ & $2.2-2.3$ & 40 & continuous & $\begin{array}{l}\text { Kakanda tailings } \\
(\mathrm{Cu} \text { and } \mathrm{Co} \\
\text { recovery in } \mathrm{RDC})\end{array}$ & 1.3 & 3 & - & - & $70-90 \%$ & [33] \\
\hline 20\% D2EHPA & - & - & $1: 1$ & $2.2-2.3$ & n.i. & continuous & $\begin{array}{l}\text { Cobalt bearing feed } \\
\text { from a cobalt } \\
\text { refinery in South } \\
\text { Africa. Fe and } \mathrm{Cu} \\
\text { were first } \\
\text { precipitated }\end{array}$ & 0.1 & 5.5 & - & - & $100 \%$ & [34] \\
\hline
\end{tabular}




\section{Materials and Methods}

Bis(2-ethylhexyl) phosphoric acid (D2EHPA, 97\%, Sigma Aldrich, Germany) was used as solvent extraction reagent as it was supplied, without any additional purification. Isopar L (Exxon Mobil, USA) was used as diluent. A synthetic solution was prepared based on the chemical composition of an original solution obtained through the acid leaching of spent lithium-ion batteries with sulfuric acid, which was investigated in detail in previous work (unpublished results). The synthetic solution was prepared using sulfates $\left(\mathrm{NiSO}_{4} \cdot 6 \mathrm{H}_{2} \mathrm{O}, \mathrm{CoSO}_{4} \cdot 7 \mathrm{H}_{2} \mathrm{O}, \mathrm{MnSO}_{4} \cdot \mathrm{H}_{2} \mathrm{O}, \mathrm{Li}_{2} \mathrm{SO}_{4}\right.$, Sigma Aldrich, Germany) and Milli-Q water. Impurities typically present in acid leach solutions from LIBs such as $\mathrm{Cu}$ and $\mathrm{Al}$ were not included into the synthetic solution because they are generally removed using conventional purification processes, for example, cementation and purification, before the solvent extraction.

Preliminary extraction tests, scrubbing, and stripping tests were performed in glass vials $(3.5 \mathrm{~mL}$ ) using a shaking machine (IKA-Vibrax, Germany) operating with 1000 vibrations per min to promote the contact between phases. The experiments were performed at room temperature. Specific conditions used in the preliminary tests are reported in the Results section. The extraction and stripping of manganese and cobalt were optimized using factorial designs of experiments and response surfaces. These methodologies are explained in detail by Montgomery [35]. For the factorial design of experiments of the extraction phase, tests were carried out using plastic containers $(50 \mathrm{~mL})$, in which the stirrer from a mixer-settler device was coupled. The stirring speed was set at $1000 \mathrm{rpm}$, and the tests were also performed at room temperature.

The $\mathrm{pH}$ of the aqueous phase was measured using a $\mathrm{pH}$ meter (Metrohm $827 \mathrm{pH}$ lab, Switzerland), and the electrode was regularly calibrated before and during the experimental procedures. The $\mathrm{pH}$ was adjusted whenever it was needed with $5 \mathrm{M}$ or $10 \mathrm{M} \mathrm{NaOH}$ to minimize the dilution effect of the feed solution. Samples from the aqueous phase were taken 10 min after finishing the contact time at the established $\mathrm{pH}$ to obtain a complete separation of phases. Chemical analysis was performed by Inductively Coupled PlasmaOptical Emission Spectroscopy (ICP-OES, iCAP ${ }^{\mathrm{TM}} 6000$ Series, USA) using samples from the aqueous phase, which were diluted in $0.5 \mathrm{M}$ nitric acid. The extraction efficiency of metals was determined by Equation (1):

$$
\% E=100 * \frac{D_{X}}{D_{X}+\left(V_{a q} / V_{\text {org }}\right)}
$$

where $V_{a q}$ and $V_{\text {org }}$ represent the volume of the aqueous phase and the volume of the organic phase, respectively, and $D_{X}$ is the distribution ratio, which describes the ratio between the concentration of a certain metal $(X)$ in the aqueous phase and in the organic phase and it can be determined by Equation (2). In some cases, the $\log D$ is used to assist the interpretation of results.

$$
D_{x}=C_{X \text { organic }} / C_{X} \text { aqueous }
$$

The separation factors $(\beta)$ between two elements ( $X$ and $Y$ ) can be calculated using Equation (3), and it is determined by the division of the distribution ratio of each element, being normally greater than one. This equation was used to determine the separation factor of manganese in preference to other metals.

$$
\beta=D_{X} / D_{Y}
$$

\section{Experimental Design}

A full $2^{\mathrm{k}}$ factorial design of experiments was used to fit a second-order linear regression model to the experimental results. To estimate the experimental uncertainty, four additional experiments were performed under the same conditions at the central level of the factors $\left(n_{C}\right.$, central point). The effects of three factors $(\mathrm{k}=3)$, each one with two levels $\left(2^{3}\right.$ factorial 
design), on the process response ( $y$, manganese extraction or cobalt extraction) were studied. The factors and levels were selected based on results from preliminary tests and on the literature review.

Experimental design of the extraction stage: The factors investigated in the design of experiments to model the extraction stage were equilibrium $\mathrm{pH}\left(x_{1}\right)$, organic to aqueous ratio, O:A $\left(x_{2}\right)$ and molar concentration of D2EHPA $\left(x_{3}\right)$. Each factor was varied in two levels.

Experimental design of the stripping stage: To model the stripping stage, the effect of the following three factors was evaluated: molar concentration of sulfuric acid $\left(x_{1}\right)$, organic to aqueous ratio, O:A $\left(x_{2}\right)$ and stripping time $\left(x_{3}\right)$. Each factor was varied in two levels.

Axial points were included ( $2 k$ axial points) in both designs to estimate the quadratic terms of the models, setting up a central composite design. Tests were performed in random order. The distance of the axial points from the central point was $\alpha=1$ (face-centered central composite design). The standard, high, and low levels of the factors are presented in Table 2.

Table 2. Factors considered in the factorial design of experiments of the extraction and stripping stages and respective levels.

\begin{tabular}{|c|c|c|c|c|c|}
\hline \multirow{2}{*}{ Stage } & \multirow{2}{*}{ Factors } & \multirow{2}{*}{ Unit } & \multicolumn{3}{|c|}{ Levels } \\
\hline & & & Low $(-1)$ & Standard (0) & High $(+1)$ \\
\hline \multirow{3}{*}{ Extraction } & Equilibrium $\mathrm{pH}\left(x_{1}\right)^{*}$ & dimensionless & 2.5 & 3.25 & 4.0 \\
\hline & Organic to aqueous phase, $\mathrm{O}: \mathrm{A}\left(x_{2}\right)$ & dimensionless & 0.5 & 1.25 & 2 \\
\hline & Concentration of D2EHPA $\left(x_{3}\right)$ & $\mathrm{M}$ & 0.4 & 0.5 & 0.6 \\
\hline \multirow{3}{*}{ Stripping } & Concentration of $\mathrm{H}_{2} \mathrm{SO}_{4}\left(x_{1}\right)$ & M & 0.05 & 1.025 & 2 \\
\hline & Organic to aqueous phase, $\mathrm{O}: \mathrm{A}\left(x_{2}\right)$ & dimensionless & 1 & 4.5 & 8 \\
\hline & Stripping time $\left(x_{3}\right)$ & $\min$ & 2 & 13.5 & 25 \\
\hline
\end{tabular}

* Equilibrium $\mathrm{pH}$ after a contact time of $10 \mathrm{~min}$, with a maximum variation of \pm 0.05 from the value defined in the design.

The process response, $y$, was used to fit the coefficients of a linear second-order regression model, using the linear least squares method. Only statistically significant variables were considered in the models ( $p$-value smaller than the significance level of 0.05 ). Analysis of variance (ANOVA) was used to assess the significance of the fitted model. The variance of the response accounted for the models was evaluated by the coefficient of determination $\left(R^{2}\right)$, and the existence of pure quadratic curvature was determined by hypothesis testing. Response surfaces and contour plots were used to assist the optimization of the processes.

\section{Results and Discussion}

\subsection{Preliminary Tests of Extraction}

Preliminary tests were performed to determine the best conditions to be further investigated in the factorial design of experiments. The extraction of $\mathrm{Mn}, \mathrm{Ni}, \mathrm{Co}$, and $\mathrm{Li}$ at different contact times can be observed in Figure 1. The mechanism of extraction of manganese using D2HEPA is very fast. The extraction of Mn was about $60 \%$ after only 5 min of contact time, and after $10 \mathrm{~min}$, the extraction achieves the maximum values (approximately 70\%). The coextraction of $\mathrm{Co}, \mathrm{Ni}$, and $\mathrm{Li}$ is slightly higher after $5 \mathrm{~min}$ of contact time, but it is still lower than $20 \%$. At 10 min of contact time, the increase in the extraction of $\mathrm{Mn}$ resulted in a decrease of the coextraction of the other metals. The coextraction of $\mathrm{Co}, \mathrm{Ni}$, and $\mathrm{Li}$ after $10 \mathrm{~min}$ of contact time was around 11, 5, and 3\%, respectively. This is in accordance with the results reported in the literature. Chen et al. [24] studied the extraction of manganese from the leaching liquor of spent LIBs using cobaltloaded D2EHPA, and they reported that the equilibrium was achieved after only $3 \mathrm{~min}$. Hossain et al. [28] also observed that the kinetics of the manganese extraction using CoD2EHPA was fast, and the equilibrium was achieved in $5 \mathrm{~min}$. Thus, low contact times are required for the extraction of manganese. 


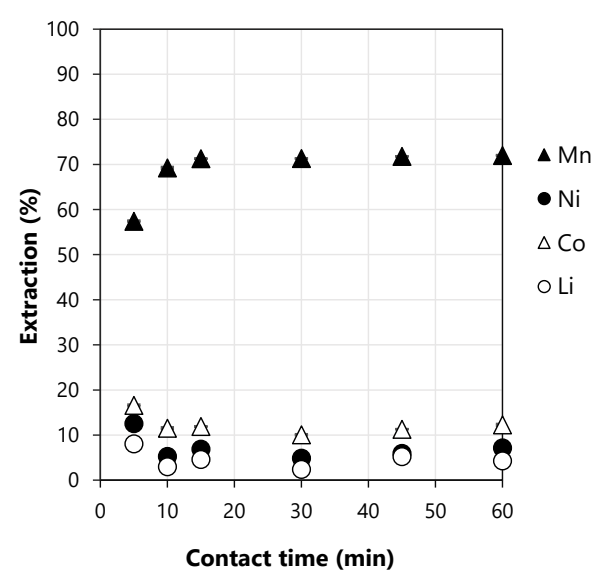

Figure 1. Extraction of metals at different leaching times. Conditions: O:A of 1:1; $0.5 \mathrm{M}$ bis(2ethylhexyl) phosphoric acid (D2EHPA) and $\mathrm{pH}$ of 3.5.

\subsection{Effect of the Concentration of Modifier (\% Volume of TBP)}

Preliminary tests using TBP (tributyl phosphate, Sigma Aldrich, Germany) as a modifier were performed to evaluate its potential to increase the extraction of manganese as well as its separation from the other metals. The extraction of $\mathrm{Mn}, \mathrm{Ni}, \mathrm{Co}$, and $\mathrm{Li}$ without using TBP and when volumetric concentrations of $2.5 \%, 5 \%$, and $10 \%$ TBP were used can be seen in Figure 2, where the error bars represent the standard deviation of triplicates. The extraction of Mn had a slight increase when the concentration of TBP was increased until $5 \%$. However, the coextraction of all other metals also increased when TBP was used as a modifier. For all evaluated metals, the extraction decreased when $10 \%$ of TBP was used. Considering that no formation of a third phase was observed, it was decided not to use TBP in the next tests.

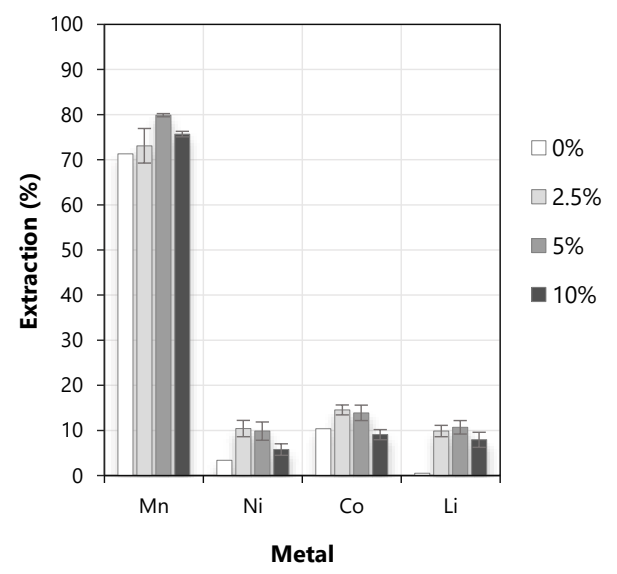

Figure 2. Extraction of metals using different volumetric concentrations of TBP as a phase modifier. Conditions: contact time of $10 \mathrm{~min}, 0.5 \mathrm{M}$ D2EHPA, equilibrium $\mathrm{pH}$ of 3.5, organic to aqueous ratio (O:A) of 1:1. Error bars represent the standard deviation of triplicates.

\subsection{Effect of the $p H$ on the Extraction of Metals}

The extraction of $\mathrm{Mn}, \mathrm{Co}, \mathrm{Li}$, and $\mathrm{Ni}$ for three different molar concentrations of D2HEPA $(0.4,0.5$, and $0.6 \mathrm{M})$ at different $\mathrm{pH}$ values can be seen in Figure 3. Some tests were performed using $0.2 \mathrm{M}$ D2EHPA, but in this case, the extraction of manganese never exceeded $30 \%$, and since this concentration is lower than the ones usually reported in the literature, further tests using 0.2 M D2EHPA were not performed. The initial $\mathrm{pH}$ of the synthetic solution based on the composition of the LIBs leach liquor was 3.8. After contacting the synthetic solution with the extractant, the $\mathrm{pH}$ of the aqueous phase decreased to about 2 . This behavior was expected, considering the mechanism of extraction of metals 
using D2EHPA (Equation (4)) described by Zhang and Cheng [14], which results in a decrease in the $\mathrm{pH}$.

$$
M^{2+}+2 \overline{(H A)_{2}} \leftrightarrows \overline{M A_{4} H_{2}}+2 H^{+}
$$

where $M$ represents the metal, $\overline{(H A)_{2}}$ represents D2EHPA in the organic phase, and $\overline{M A_{4} H_{2}}$ represents the metal-organic complex [14].

(a)

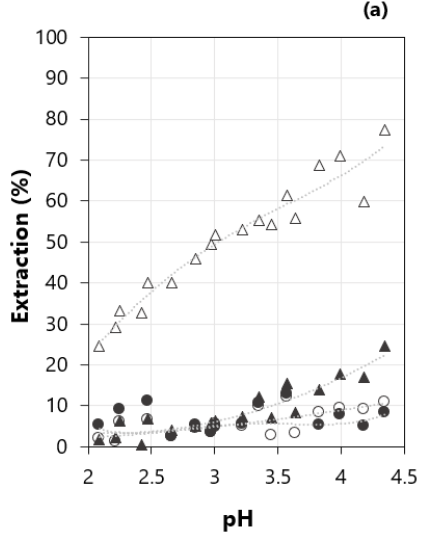

(b)

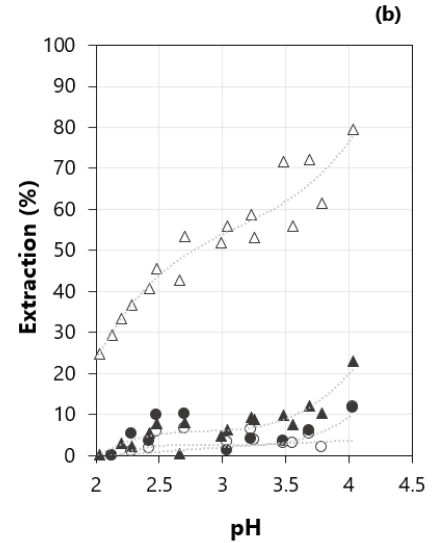

(c)

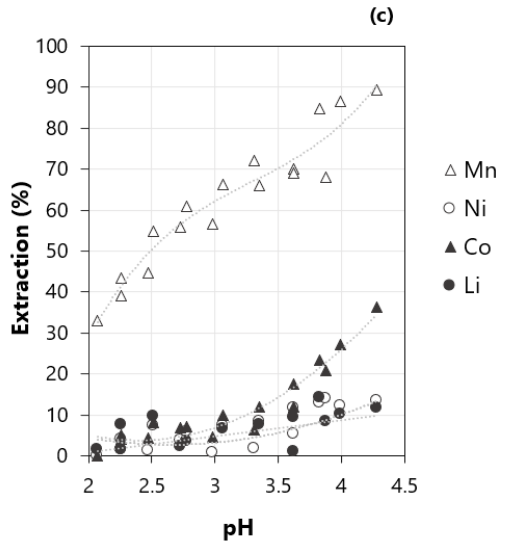

Figure 3. Extraction of metals using different molar concentrations of D2EHPA: (a) 0.4 M D2EHPA, (b) 0.5 M D2EHPA, (c) 0.6 M D2EHPA. Conditions: O:A of 1:1, contact time of $10 \mathrm{~min}$.

The extraction of manganese increased with the $\mathrm{pH}$ for the three different concentrations of D2EHPA, but when the $\mathrm{pH}$ was increased to about 4, the coextraction of other metals was also more pronounced, mainly of cobalt. The increase in the molar concentration of D2HEPA also promoted an increase in the extraction of manganese, which was more pronounced when 0.6 M D2EHPA was used.

\subsection{Effect of the Organic to Aqueous Ratio (O:A)}

Preliminary tests were performed to evaluate the effect of the O:A ratio on the extraction of metals (Figure 4). The extraction of manganese increased with the O:A ratio (Figure 4a); however, the coextraction of cobalt also increased with the O:A ratio. For this reason, $\mathrm{O}$ :A ratios from 0.5 to 2 were further investigated in the factorial design of experiments. The isotherm representing the distribution of manganese in the aqueous and organic phase can be seen in Figure $4 \mathrm{~b}$. The extraction of manganese can be theoretically achieved after two extraction stages using an O:A ratio of 1.25.

(a)

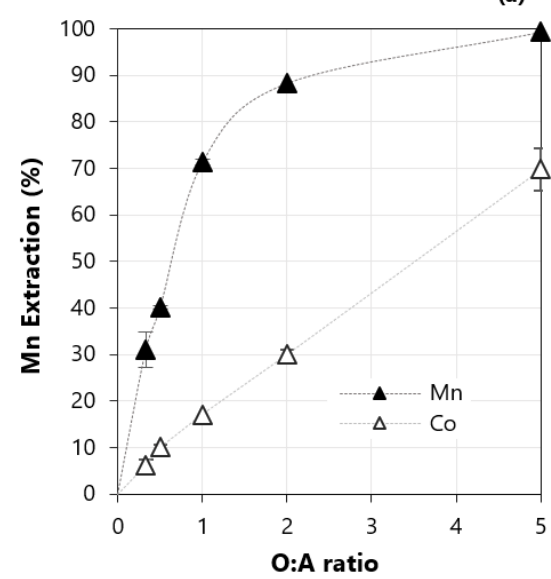

(b)

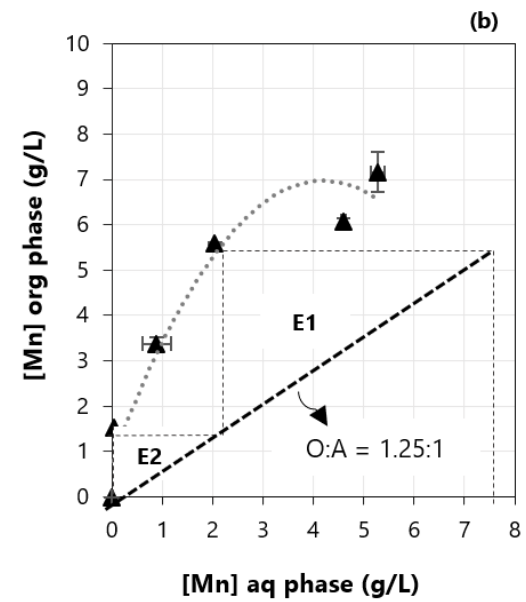

Figure 4. (a) Extraction of manganese and cobalt using different O:A ratios and (b) McCabe-Thiele diagram of the Mn extraction. Conditions: equilibrium pH of 3.5, 0.5 M D2EHPA, contact time of $10 \mathrm{~min}$. Error bars represent the standard deviation of triplicates. 


\subsection{Extraction Stage: Factorial Design of Experiments and Regression Model}

The conditions of the factorial design of experiments and respective responses (manganese and cobalt extraction) for each experiment are presented in Table 3. Tests from 1 to 8 correspond to the base $2^{3}$ design. Tests from 9 to 12 are the replicates in the central point of the design and were used to determine the experimental error. Tests from 13 to 18 are the axial points added to the design. All the tests were performed at room temperature using a contact time of $10 \mathrm{~min}$. The concentrations of metals in the raffinate and in the organic phase are reported in the Supplementary Materials (Table S1), as well as the extraction of $\mathrm{Ni}$ and $\mathrm{Li}$, which in general remain at low values. The Supplementary Material (Table S2) also reports the distribution ratios $(D)$ and separation factors $(\beta)$.

Table 3. Conditions of the experimental design and results for the extraction of manganese and cobalt.

\begin{tabular}{cccccccccc}
\hline \multirow{2}{*}{$\begin{array}{c}\text { Run } \\
\text { Order }\end{array}$} & Std & \multicolumn{2}{c}{ Coded Variables } & \multicolumn{2}{c}{ Real Variables } & \multicolumn{2}{c}{$\begin{array}{c}\text { Response } \\
\text { (Extraction) }\end{array}$} \\
\cline { 3 - 10 } & Order & $x_{\mathbf{1}}$ & $\boldsymbol{x}_{\mathbf{2}}$ & $\boldsymbol{x}_{\mathbf{3}}$ & $\mathbf{p H}$ & O:A & D2EHPA & Mn (\%) & Co (\%) \\
\hline 6 & 1 & -1 & -1 & -1 & 2.5 & 0.5 & 0.4 & 20 & 2 \\
11 & 2 & 1 & -1 & -1 & 4 & 0.5 & 0.4 & 51 & 12 \\
10 & 3 & -1 & 1 & -1 & 2.5 & 2 & 0.4 & 61 & 4 \\
4 & 4 & 1 & 1 & -1 & 4 & 2 & 0.4 & 92 & 23 \\
14 & 5 & -1 & -1 & 1 & 2.5 & 0.5 & 0.6 & 30 & 4 \\
5 & 6 & 1 & -1 & 1 & 4 & 0.5 & 0.6 & 57 & 8 \\
12 & 7 & -1 & 1 & 1 & 2.5 & 2 & 0.6 & 79 & 1 \\
13 & 8 & 1 & 1 & 1 & 4 & 2 & 0.6 & 97 & 44 \\
\hline 18 & 9 & 0 & 0 & 0 & 3.25 & 1.25 & 0.5 & 72 & 4 \\
8 & 10 & 0 & 0 & 0 & 3.25 & 1.25 & 0.5 & 73 & 5 \\
7 & 11 & 0 & 0 & 0 & 3.25 & 1.25 & 0.5 & 73 & 5 \\
9 & 12 & 0 & 0 & 0 & 3.25 & 1.25 & 0.5 & 70 & 4 \\
\hline 15 & 13 & -1 & 0 & 0 & 2.5 & 1.25 & 0.5 & 48 & 1 \\
16 & 14 & 1 & 0 & 0 & 4 & 1.25 & 0.5 & 88 & 25 \\
2 & 15 & 0 & -1 & 0 & 3.25 & 0.5 & 0.5 & 38 & 9 \\
1 & 16 & 0 & 1 & 0 & 3.25 & 2 & 0.5 & 91 & 16 \\
17 & 17 & 0 & 0 & -1 & 3.25 & 1.25 & 0.4 & 63 & 7 \\
3 & 18 & 0 & 0 & 1 & 3.25 & 1.25 & 0.6 & 81 & 3 \\
\hline
\end{tabular}

The adjusted regression model $(y)$ for the extraction of manganese and the extraction of cobalt are represented by Equations (5) and (6), respectively. The models are only valid for the range of values tested in this study, and they only include factors with a statistically significant effect on the responses $(\alpha=0.05)$.

$$
\begin{gathered}
M n(\%)=72.0+14.7 x_{1}+22.3 x_{2}+5.7 x_{3}-7.4 x_{2}^{2} \\
\text { Co }(\%)=6.6+10.0 x_{1}+5.2 x_{2}+6.0 x_{1} x_{2}+3.7 x_{1} x_{2} x_{3}+4.7 x_{1}^{2}
\end{gathered}
$$

The results of the analysis of variance of the fitted models for the extraction of manganese and cobalt are presented in Table 4, which was adapted from the ANOVA table from the Regression Analysis tool of Excel (Analysis ToolPak add-in). The replicates in the central level of the design allow estimating the experimental pure error and decomposing the Residual Sum of Squares (RSS) into the Sum of Squares due to Pure Error (SSPE) and the Sum of Squares due to Lack of Fit (SSLOF). The presence of curvature was verified for both models using the pure curvature testing ( $p$-value $=0.048$ and 0.046 for manganese and cobalt, respectively). The significance of the fitted models is indicated by the results of the $F$-test. The model adequacy was assessed by the Lack of Fit (LOF) test, but the results were lower than the significance level $(\alpha=0.05)$ for both models, given the low experimental error in the central point of the design and a small variance of the experimental error when compared to the residual error. 
Table 4. Results of the analysis of variance of the fitted models for the extraction of manganese and cobalt.

\begin{tabular}{|c|c|c|c|c|c|c|}
\hline Respon & Source & Degree of Freedom & Sum of Squares & Mean Square & F-Value & $p$-Value \\
\hline \multirow{5}{*}{$\begin{array}{l}\text { Manganese } \\
\text { extraction }\end{array}$} & Regression & 10 & 7964.8 & 796.5 & 43.6 & $2.4 \times 10^{-5}$ \\
\hline & Residual & 7 & 127.9 & 18.3 & - & - \\
\hline & Lack of fit & 4 & 120.4 & 30.1 & 12.2 & $3.4 \times 10^{-2}$ \\
\hline & Pure error & 3 & 7.4 & 2.5 & - & - \\
\hline & Totals & 17 & 8092.7 & - & - & - \\
\hline \multirow{5}{*}{$\begin{array}{c}\text { Cobalt } \\
\text { extraction }\end{array}$} & Regression & 10 & 1988.3 & 198.8 & 17.6 & $4.9 \times 10^{-4}$ \\
\hline & Residual & 7 & 79.2 & 11.3 & - & \\
\hline & Lack of fit & 4 & 78.0 & 19.5 & 49.2 & $4.6 \times 10^{-3}$ \\
\hline & Pure error & 3 & 1.2 & 0.4 & - & - \\
\hline & Totals & 17 & 2067.5 & - & - & - \\
\hline
\end{tabular}

Pareto charts of the standardized effects of the variables on the responses are presented in Figure $5 \mathrm{a}$ for the manganese extraction and in Figure $5 \mathrm{~b}$ for the cobalt extraction. The standardized effects were calculated by dividing each coefficient by its standard error. The standardized effects correspond to the $t$-statistic values. A variable is considered statistically significant if its $p$-value is smaller than the defined significance level ( 0.05 for a confidence level of $95 \%$ ). The significance level is identified in the graphs by dashed lines (2.36 at abscissa) and it corresponds to the 0.975 quartile in the Student's distribution, with seven degrees of freedom (total number of estimated coefficients subtracted from the total number of experiments). Thus, the effect of variables and their interactions is more significant as they are to the right of the red dashed line.
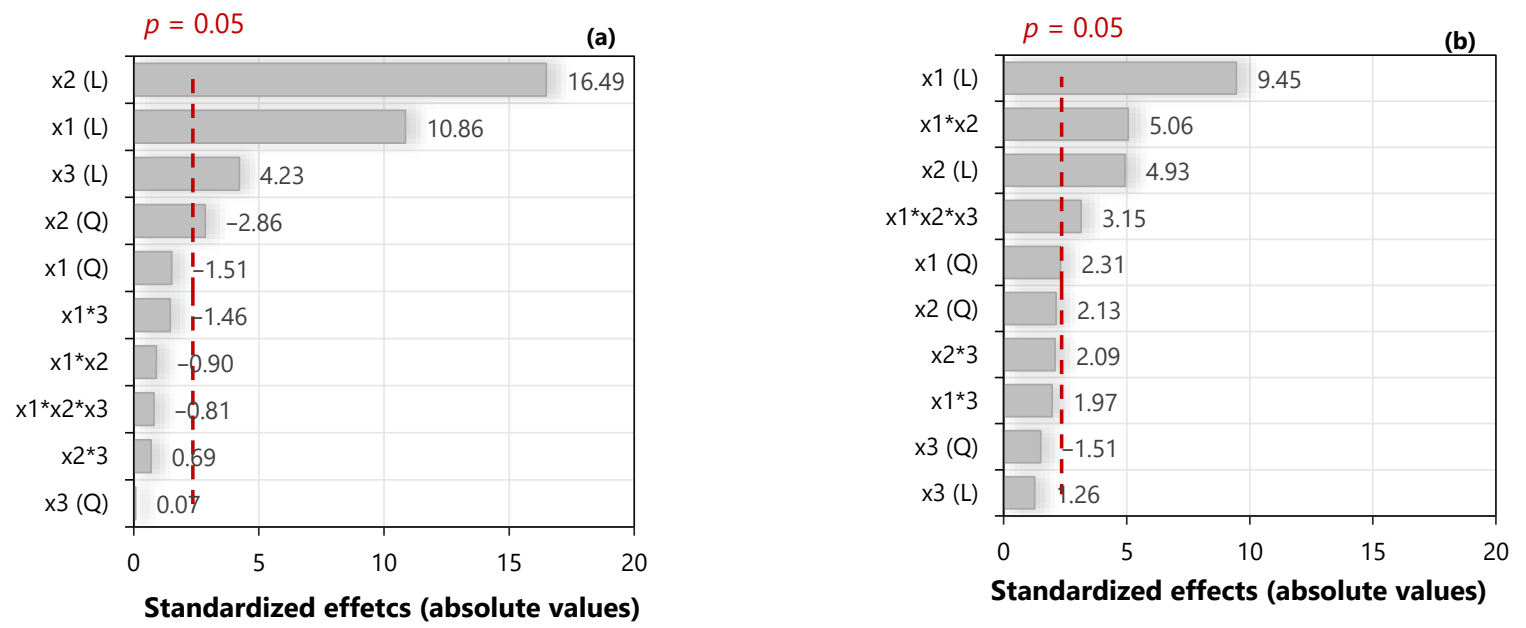

Figure 5. Pareto charts of the absolute values of the standardized effects of the factors for the regression model for (a) manganese extraction and (b) cobalt extraction with a significance level $\alpha=0.05$. Legend: $x_{1}: \mathrm{pH}, x_{2}$ : O:A ratio, $x_{3}$ : molar concentration of D2EHPA, (Q): quadratic terms, (L): linear terms.

The variables with higher effects on the manganese extraction were $x_{2}$ (O:A ratio), $x_{1}$ $(\mathrm{pH})$, and $x_{3}$ (molar concentration of D2EHPA). The quadratic effect of the factor $x_{2}$ is also significant in the extraction of manganese. Then, it can be concluded that the extraction of manganese increases with the increase of the $\mathrm{pH}$, extractant concentration, and the $\mathrm{O}: \mathrm{A}$ ratio. The quadratic terms $x_{1}{ }^{2}$ and $x_{3}{ }^{2}$, as well as all the interactions, did not present a significant effect on the manganese extraction in the range of values tested in this work (at a confidence level of $95 \%$ ).

Regarding the extraction of cobalt (Figure $5 b$ ), the main effects were accounted for the variables $x_{1}(\mathrm{pH}), x_{2}$ (O:A ratio) and the interactions of $x_{1} x_{2}$ and $x_{1} x_{2} x_{3}$, with a positive effect on the response with the increase of their levels. The quadratic terms $x_{1}{ }^{2}, x_{2}{ }^{2}$, and $x_{3}{ }^{2}$, the factor $x_{3}$ (molar concentration of D2EHPA), as well as the interactions $x_{1} x_{3}$ and 
$x_{2} x_{3}$ did not present a significant effect on the extraction of cobalt in the range of values considered for a confidence level of $95 \%$.

The coefficient of determination $\left(R^{2}\right)$ was used to assess the goodness of fit of the models. The model for the manganese extraction presented an $R^{2}=0.98$ and for the cobalt extraction an $R^{2}=0.96$. This coefficient indicates that $98 \%$ and $96 \%$ of the response variability is explained by the fitted models, respectively. The relation between the experimentally observed responses for the extraction of manganese (Figure 6a) and cobalt (Figure 6b) is represented in the scatter plots below. This relation demonstrates that the adjusted models can provide a good fit to the experimental results under the range of values considered in the study.

(a)

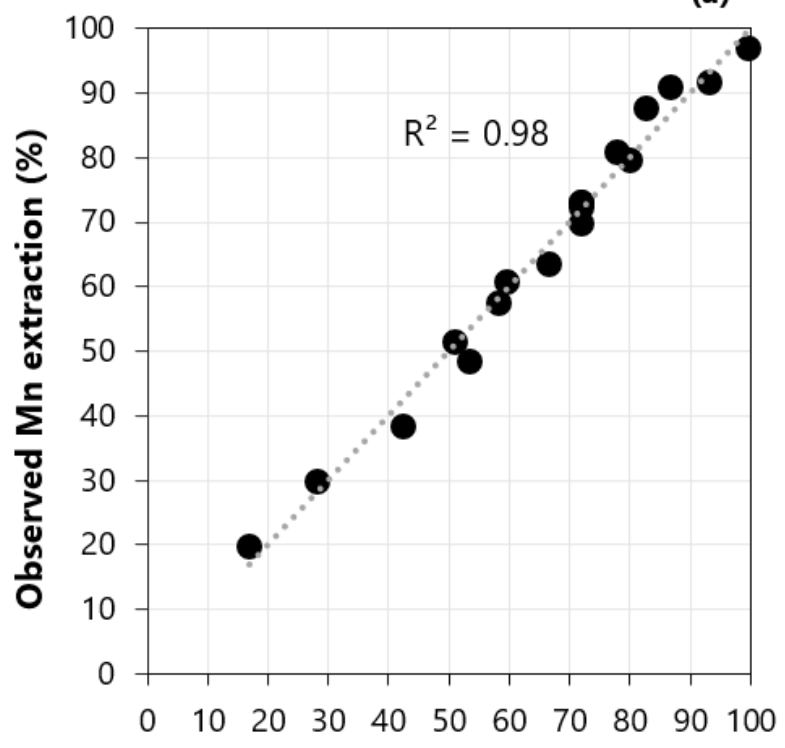

Predicted Mn extraction (\%) (b)

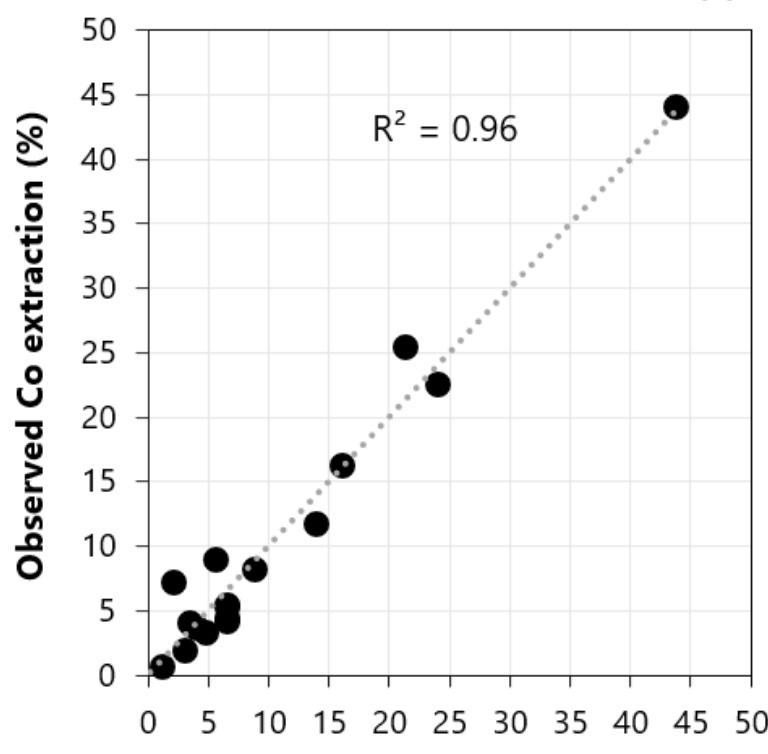

Predicted Co extraction (\%)

Figure 6. Responses predicted by the model versus experimentally observed: (a) manganese extraction and (b) cobalt extraction.

\subsection{Response Surfaces: Extraction of Manganese and Cobalt}

To help to understand the effect of the different factors on the extraction of manganese and cobalt, response surfaces were used. They were depicted using contour plots to show a clear representation of the surfaces. Contour plots are represented by a set of lines of constant response, being constructed in planes defined by pairs of variables. Therefore, each line represents a particular response of the fitted model.

The contour plots representing the manganese extraction when the factor $x_{1}(\mathrm{pH})$ was fixed at its low level $(-1, \mathrm{pH}=2.5)$, standard level $(0, \mathrm{pH}=3.2)$, and high level $(+1, \mathrm{pH}=4)$ can be seen in Figure $7 \mathrm{a}-\mathrm{c}$, respectively. The responses for the extraction of cobalt under these same conditions are represented in Figure 7d-f. To construct the contour plots, the level of the factors $x_{2}$ (O:A ratio) and $x_{3}$ (molar concentration of D2EHPA) was changed from the low to the high level. The responses ( $y=\%$ extraction) are represented by legends on the left of each graph. Results are only valid in the range of values considered in this study. 


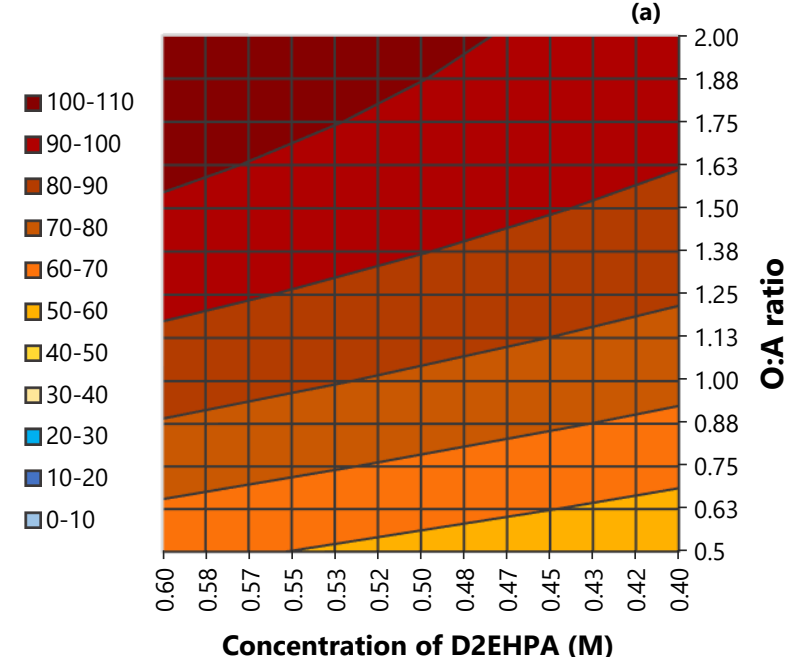

(d)

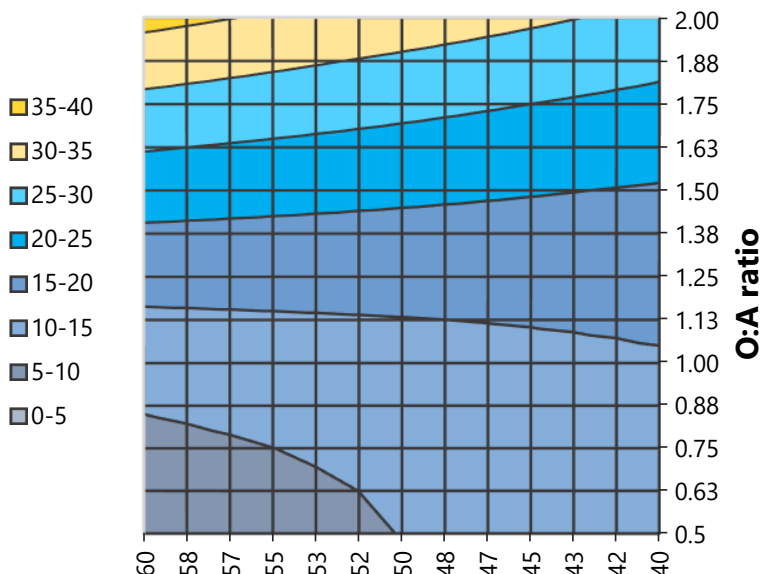

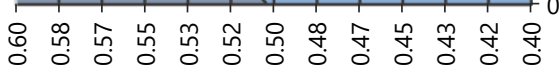

Concentration of D2EHPA (M)

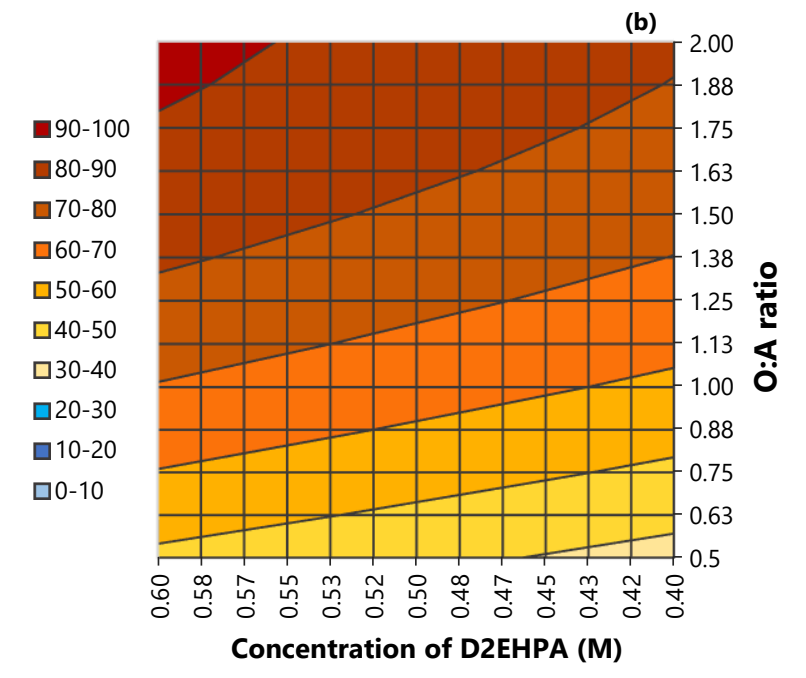

(e)

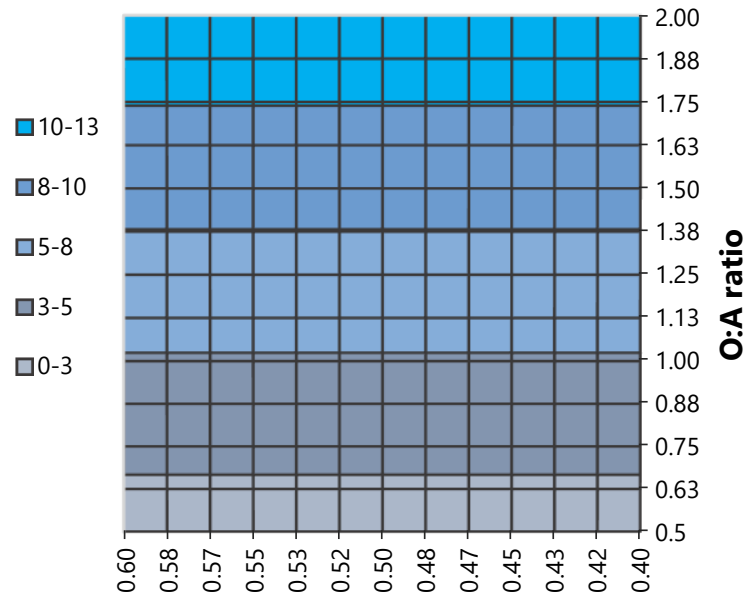

Concentration of D2EHPA (M)

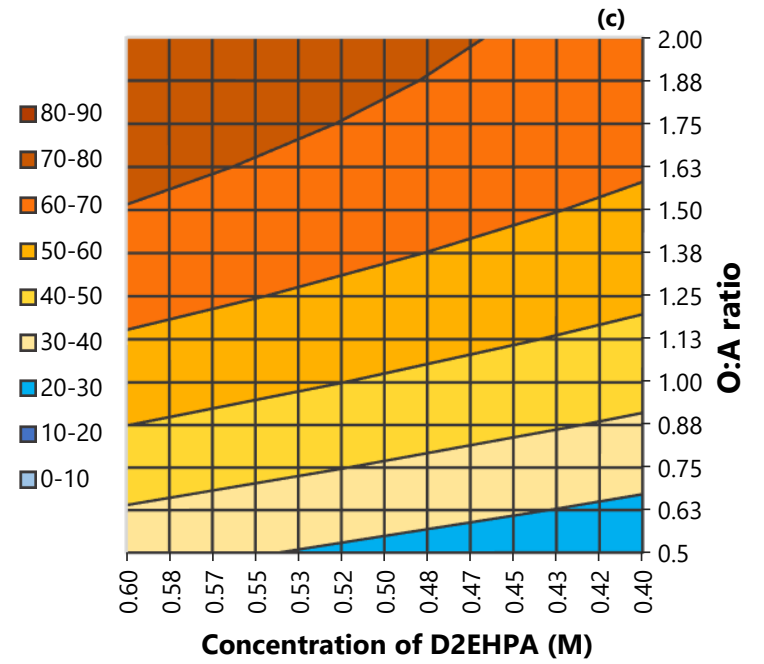

(f)

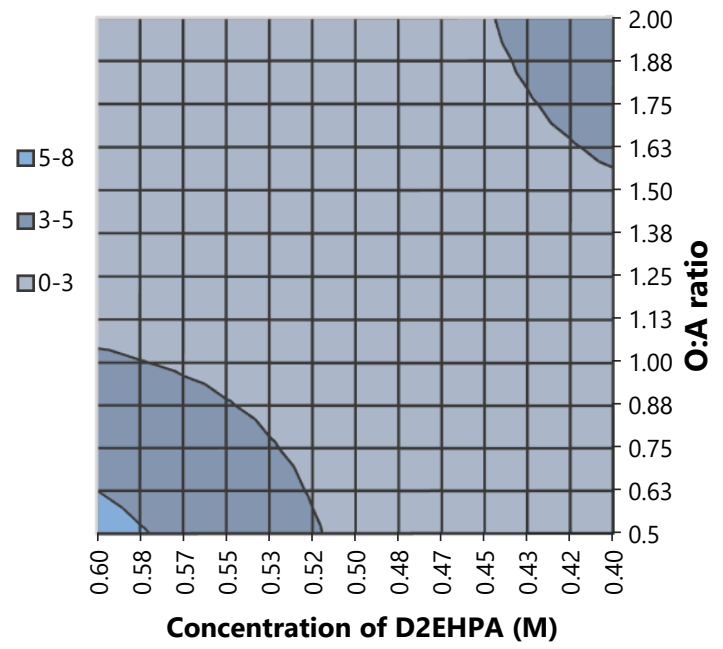

Concentration of D2EHPA (M)

Figure 7. Contour plots representing the $(\mathbf{a}-\mathbf{c})$ extraction of manganese and the $(\mathbf{d}-\mathbf{f})$ coextraction of cobalt when the $\mathrm{pH}$ was set at $2.5(\mathbf{a}, \mathbf{d})$, at $\mathrm{pH}$ of $3.25(\mathbf{b}, \mathbf{e})$ and at $\mathrm{pH} 4(\mathbf{c}, \mathbf{f})$. 
The extraction of manganese when the $\mathrm{pH}$ was set at 2.5 is represented in Figure 7a. High manganese extractions can be achieved for any level of concentration of D2EHPA provided that the O:A ratio is also at a high level, which is explained by the highest effect of the $\mathrm{O}: \mathrm{A}$ ratio on the response. At the lowest $\mathrm{pH}$, the lowest extraction of manganese was verified at the lowest level of the O:A ratio (0.5:1) and at the lowest concentration of extractant $(0.4 \mathrm{M})$. On the other hand, when the $\mathrm{pH}$ was 2.5 , the highest extraction of manganese was observed at the highest level of the O:A ratio (2:1) and at the highest level of concentration of D2EHPA $(0.6 \mathrm{M})$. However, when the $\mathrm{pH}$ was 2.5 , the extraction of manganese never exceeded 70-80\%, which can be explained by the mechanism of the reaction of D2HPA, by which an increase in the concentration of $\mathrm{H}^{+}$ions will move the equilibrium to the left side, hiding the formation of products. When the $\mathrm{pH}$ was set at 2.5 , it is possible to observe in Figure $7 \mathrm{~d}$ that the extraction of cobalt was kept at a very low level and never exceeded 5\%, which was reached only when high concentrations of D2EHPA or high O:A ratios were employed.

The behavior of the extraction of manganese when the $\mathrm{pH}$ was 2 was similar to the one when the $\mathrm{pH}$ was 3.25, as can be observed in Figure 7b. However, the increase in the $\mathrm{pH}$ resulted in an increase in the highest extraction of manganese, which was raised to $80-90 \%$. The lowest extraction of manganese at $\mathrm{pH} 3.25$ was also obtained when the concentration of D2EHPA and the O:A ratio were at their lowest levels ( $0.4 \mathrm{M}$ and $0.5: 1$, respectively). The highest extraction of manganese at $\mathrm{pH} 3.25$ was achieved when the other two factors were at the highest level (0.6 M and 2:1). Extractions of manganese above $70 \%$ can be obtained for the whole range of values tested for the concentration of D2EHPA, provided that the $\mathrm{O}: \mathrm{A}$ ratio is at least 1.4:1. When the $\mathrm{pH}$ was set at the standard level (3.25), the extraction of cobalt is mainly dependent on the O:A ratio (Figure 7e). Thus, it is possible to keep the coextraction of cobalt below $8 \%$ provided that the $\mathrm{O}$ :A ratio does not exceed around 1.4:1.

Contour plots representing the extraction of manganese when the $\mathrm{pH}$ was set at 4 can be seen in Figure 7c. The extraction of manganese reached higher values when the other two factors were combined at a higher $\mathrm{pH}$, which is explained by the significant effect of the $\mathrm{pH}$ on the response, as it was discussed in the regression analysis. At the highest $\mathrm{pH}$, the extraction of manganese was always above $50 \%$. The lowest extraction was obtained when the concentration of D2HEPA and the O:A ratio were at the lowest level (0.4 $\mathrm{M}$ and $0.5: 1$, respectively). When both factors were increased to the highest level, the extraction of manganese achieved the maximum results. It is important to highlight that for certain conditions, the fitted model slightly overestimated the responses (above 100\%). The coextraction of cobalt also increased to higher values when the $\mathrm{pH}$ was set at the highest level (Figure 7f), which is also compatible with the significant effect of the $\mathrm{pH}$ on the cobalt response, which was observed in the regression analysis. The highest coextraction of cobalt was observed when the concentration of D2EHPA and the O:A ratio were at their highest levels (0.6 M and 2:1, respectively) and achieved around 35\%. At $\mathrm{pH} 4$, the coextraction of cobalt remained at lower levels when both the O:A ratio and concentration of D2EHPA were set at lower levels.

Considering the results using the fitted models, to keep the coextraction of cobalt low even though obtaining high extractions of manganese, the $\mathrm{pH}, \mathrm{O}: \mathrm{A}$ ratio, and concentration of D2EHPA should be kept at intermediate levels. For this reason, the next stages (scrubbing and stripping) were studied using a loaded organic obtained at the central level of the tested factors ( $\mathrm{pH}$ of 3.25, O:A 1.25:1, and 0.5 M D2EHPA). The concentration of the loaded organic obtained at these conditions to be used in the next stages was compatible with the results of the factorial design of experiments.

\subsection{Scrubbing of the Loaded Organic}

According to Ritcey and Ashbrook [36], scrubbing usually refers to the removal of unwanted coextracted species in the loaded organic. The purpose of scrubbing the organic phase is to replace coextracted or mechanically entrained $\mathrm{Co}, \mathrm{Ni}$, or Li together with Mn [20]. Although it can be considered an important stage to purify the loaded organic 
and selectively remove some undesired metals, the scrubbing stage was not studied in detail in this work, and the scrubbing conditions proposed by Peng et al. [20] were used. Thus, the loaded organic obtained using the standard conditions of the factorial design of experiments was scrubbed twice with a pure solution containing $4 \mathrm{~g} / \mathrm{L}$ Mn prepared using $\mathrm{MnSO}_{4} \cdot \mathrm{H}_{2} \mathrm{O}$, without $\mathrm{pH}$ adjustment (pH: 4.4) for $10 \mathrm{~min}$ at an O:A ratio of 10:1. The final composition of the scrubbing solutions (1 and 2) after contact with the loaded organic and the resultant organic phase is presented in Table 5 .

Table 5. Composition of the scrubbing solutions and the resultant organic phase after two scrubbing stages with $4 \mathrm{~g} / \mathrm{L} \mathrm{Mn}$ (O:A of 10:1, contact time of $10 \mathrm{~min})$.

\begin{tabular}{ccccc}
\hline \multirow{2}{*}{ Solution } & \multicolumn{4}{c}{ Concentration $(\mathbf{g} / \mathbf{L})$} \\
\cline { 2 - 5 } & $\mathbf{M n}$ & $\mathbf{C o}$ & $\mathbf{N i}$ & $\mathbf{L i}$ \\
\hline Feed solution & 7.4 & 18.7 & 7.2 & 1.1 \\
Aqueous phase (after extraction) & 2.1 & 18.0 & 7.0 & 1.0 \\
Scrubbing solution 1 (aqueous phase) & 0.8 & 3.0 & 0.3 & 0.1 \\
Scrubbing solution 2 (aqueous phase) & 2.1 & 1.9 & $<0.1$ & $<0.1$ \\
Organic phase & 4.7 & 0.1 & 0.1 & $<0.1$ \\
\hline
\end{tabular}

\subsection{Stripping Stage: Factorial Design of Experiments and Regression Model}

The experimental conditions of the factorial design for the stripping of the loaded organic and respective responses are presented in Table 6 . The final concentrations of manganese and cobalt $(\mathrm{g} / \mathrm{L})$ in the stripping product were considered as the process responses. All experiments were performed at room temperature after two scrubbing stages (detailed in Section 3.7).

Table 6. Conditions of the experimental design and results for the stripping of cobalt and manganese.

\begin{tabular}{|c|c|c|c|c|c|c|c|c|c|}
\hline \multirow{2}{*}{$\begin{array}{c}\text { Random } \\
\text { Order }\end{array}$} & \multirow{2}{*}{ Std Order } & \multicolumn{3}{|c|}{ Coded Variables } & \multicolumn{3}{|c|}{ Real Variables } & \multicolumn{2}{|c|}{ Response } \\
\hline & & $x_{1}$ & $x_{2}$ & $x_{3}$ & {$\left[\mathrm{H}_{2} \mathrm{SO}_{4}\right]$} & O:A & Time & $\operatorname{Mn}(g / L)$ & Co $(g / L)$ \\
\hline 9 & 1 & -1 & -1 & -1 & 0.05 & 1 & 2 & 4 & 0.06 \\
\hline 14 & 2 & 1 & -1 & -1 & 2 & 1 & 2 & 4 & 0.05 \\
\hline 4 & 3 & -1 & 1 & -1 & 0.05 & 8 & 2 & 11 & 0.31 \\
\hline 2 & 4 & 1 & 1 & -1 & 2 & 8 & 2 & 19 & 0.26 \\
\hline 15 & 5 & -1 & -1 & 1 & 0.05 & 1 & 25 & 5 & 0.08 \\
\hline 11 & 6 & 1 & -1 & 1 & 2 & 1 & 25 & 5 & 0.07 \\
\hline 3 & 7 & -1 & 1 & 1 & 0.05 & 8 & 25 & 10 & 0.41 \\
\hline 8 & 8 & 1 & 1 & 1 & 2 & 8 & 25 & 28 & 0.42 \\
\hline 16 & 9 & 0 & 0 & 0 & 1.025 & 4.5 & 13.5 & 17 & 0.26 \\
\hline 5 & 10 & 0 & 0 & 0 & 1.025 & 4.5 & 13.5 & 16 & 0.24 \\
\hline 7 & 11 & 0 & 0 & 0 & 1.025 & 4.5 & 13.5 & 16 & 0.24 \\
\hline 1 & 12 & 0 & 0 & 0 & 1.025 & 4.5 & 13.5 & 17 & 0.27 \\
\hline 18 & 13 & -1 & 0 & 0 & 0.05 & 4.5 & 13.5 & 9 & 0.15 \\
\hline 12 & 14 & 1 & 0 & 0 & 2 & 4.5 & 13.5 & 17 & 0.26 \\
\hline 10 & 15 & 0 & -1 & 0 & 1.025 & 1 & 13.5 & 5 & 0.07 \\
\hline 6 & 16 & 0 & 1 & 0 & 1.025 & 8 & 13.5 & 23 & 0.36 \\
\hline 13 & 17 & 0 & 0 & -1 & 1.025 & 4.5 & 2 & 14 & 0.21 \\
\hline 17 & 18 & 0 & 0 & 1 & 1.025 & 4.5 & 25 & 22 & 0.34 \\
\hline
\end{tabular}

The regression models for the stripping of manganese and cobalt are represented by Equations (7) and (8), respectively, and only factors with a statistically significant effect on the responses were inserted in the models $(\alpha=0.05)$. The models are only valid for the range of values tested in this study.

$$
M n(g / L)=16.9+3.4 x_{1}+6.8 x_{2}+2.0 x_{3}+3.3 x_{1} x_{2}-4.0 x_{1}^{2}-3.1 x_{2}^{2}
$$




$$
\text { Co }(g / L)=0.25+0.14 x_{2}+0.04 x_{3}+0.03 x_{2} x_{3}
$$

The results of the analysis of variance of the models are presented in Table 7. The presence of curvature was verified only for the model representing the manganese stripping with the pure curvature testing $(p$-value $=0.04)$. The results of the $F$-test can be related to the significance of the fitted models. The model adequacy was assessed by the LOF test, but the result for the manganese stripping was lower than the significance level $(\alpha=0.05)$, which can be related to the low experimental error in the central point of the design.

Table 7. Results of the analysis of variance of the fitted models for the stripping of manganese and cobalt.

\begin{tabular}{|c|c|c|c|c|c|c|}
\hline \multicolumn{2}{|c|}{ Response Source } & \multirow{2}{*}{$\begin{array}{c}\begin{array}{c}\text { Degree of } \\
\text { Freedom }\end{array} \\
10\end{array}$} & \multirow{2}{*}{$\begin{array}{c}\begin{array}{c}\text { Sum of } \\
\text { Squares }\end{array} \\
880.2\end{array}$} & \multirow{2}{*}{$\begin{array}{c}\text { Mean Square } \\
88.0\end{array}$} & \multirow{2}{*}{$\begin{array}{c}\text { F-Value } \\
20.4\end{array}$} & \multirow{2}{*}{$\begin{array}{c}p \text {-Value } \\
3.0 \times 10^{-4}\end{array}$} \\
\hline \multirow{5}{*}{$\begin{array}{l}\text { Concentration } \\
\text { of manganese }\end{array}$} & Regression & & & & & \\
\hline & Residual & 7 & 30.2 & 4.3 & - & - \\
\hline & Lack of fit & 4 & 28.7 & 7.2 & 13.9 & $2.8 \times 10^{-2}$ \\
\hline & Pure error & 3 & 1.5 & 0.5 & - & - \\
\hline & Totals & 17 & 910.4 & - & - & - \\
\hline \multirow{5}{*}{$\begin{array}{c}\text { Concentration } \\
\text { of cobalt }\end{array}$} & Regression & 10 & 0.2 & $2.4 \times 10^{-2}$ & 21.4 & $2.6 \times 10^{-4}$ \\
\hline & Residual & 7 & $7.93 \times 10^{-3}$ & $1.1 \times 10^{-3}$ & - & - \\
\hline & Lack of fit & 4 & $7.33 \times 10^{-3}$ & $1.8 \times 10^{-3}$ & 9.0 & $5.1 \times 10^{-2}$ \\
\hline & Pure error & 3 & $6.08 \times 10^{-4}$ & $2.0 \times 10^{-4}$ & - & - \\
\hline & Totals & 17 & 0.2 & - & - & - \\
\hline
\end{tabular}

Pareto charts of the standardized effects of the variables on the responses are presented in Figure 8. A significant effect on the stripping of manganese (Figure $8 \mathrm{~b}$ ) was accounted for the three main variables: $x_{1}$ (concentration of $\left.\mathrm{H}_{2} \mathrm{SO}_{4}\right), x_{2}\left(\mathrm{O}: \mathrm{A}\right.$ ratio), and $x_{3}$ (stripping time). The interaction effect of $x_{1}$ and $x_{2}$ was also significant, as well as the effect of the quadratic term $x_{1}{ }^{2}$. Thus, the stripping of manganese will increase with the increase of the levels of these three variables. The quadratic terms $x_{2}{ }^{2}$ and $x_{3}{ }^{2}$, as well as all the other interactions, did not have a significant effect on the manganese stripping, considering the range of values tested at a confidence level of $95 \%$. Only the variables $x_{2}$ (O:A ratio) and $x_{3}$ (stripping time) had a positive and significant effect on the stripping of cobalt (Figure 8b). Thus, the concentration of acid did not show a significant effect on the stripping of cobalt in the tested range nor did it have all the interactions and quadratic terms (at a confidence level of $95 \%)$.
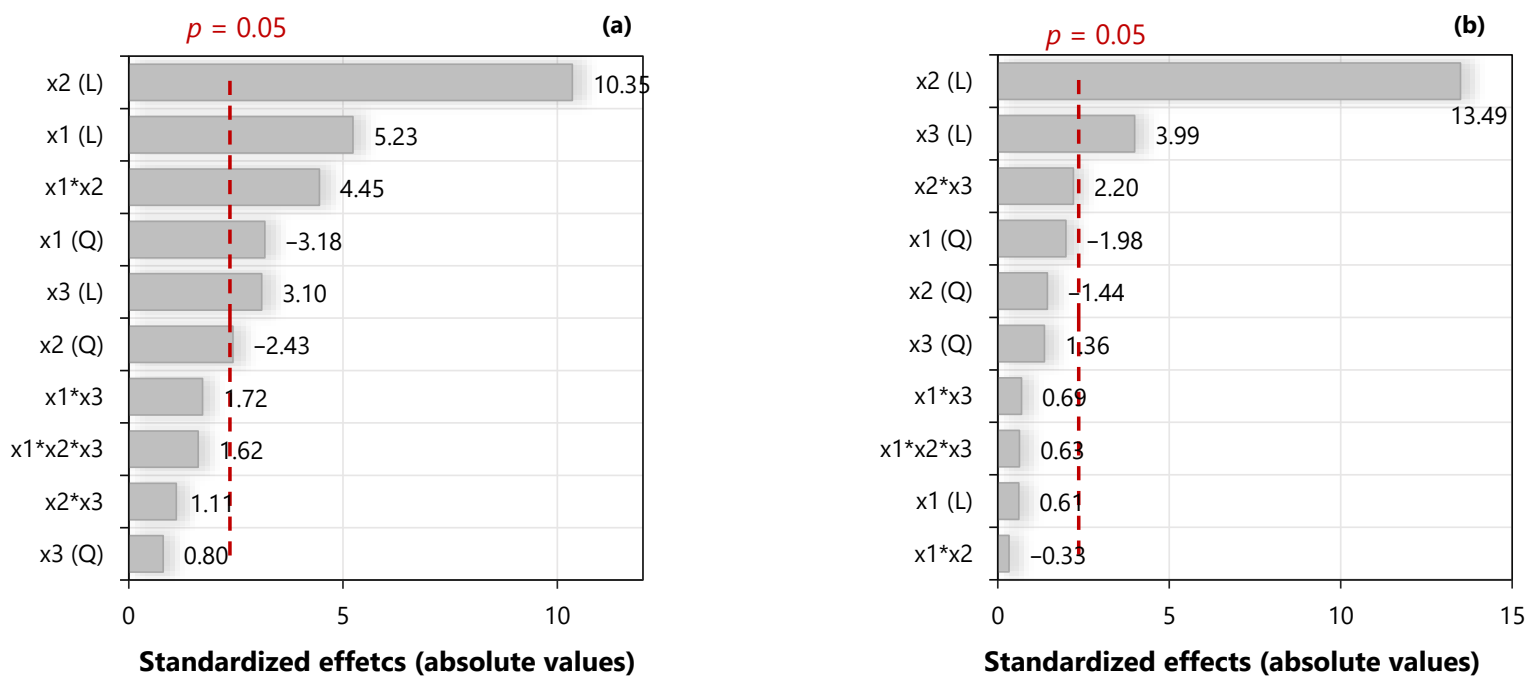

Figure 8. Pareto charts of the absolute values of the standardized effects of the factors for the regression model for the (a) manganese stripping and (b) for the cobalt stripping. Significance level $\alpha=0.05$. Legend: $x_{1}$ : molar concentration of $\mathrm{H}_{2} \mathrm{SO}_{4}$, $x_{2}$ : O:A ratio, $x_{3}$ : stripping time, $(\mathrm{Q})$ : quadratic terms, $(\mathrm{L})$ : linear terms. 
Both models presented an $R^{2}=0.97$, which is indicative that a large proportion of the variance of the response can be explained by the independent variables, considering the range of values tested in the experiments. The relation between the experimentally observed responses and those obtained using the fitted model for the stripping of manganese and cobalt are represented in Figure 9a,b, respectively, which illustrates how the models provide a good fit to the experimental results.

(a)

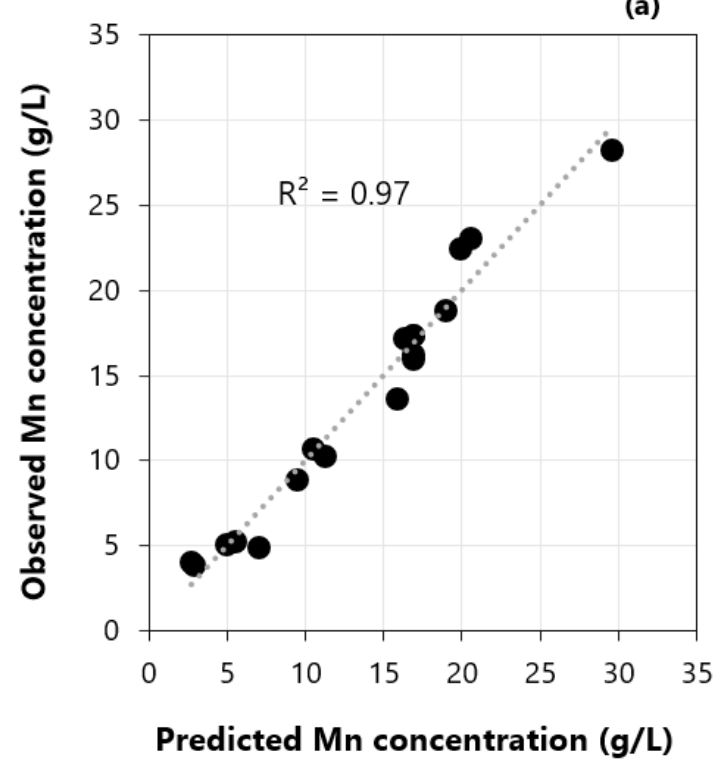

(b)

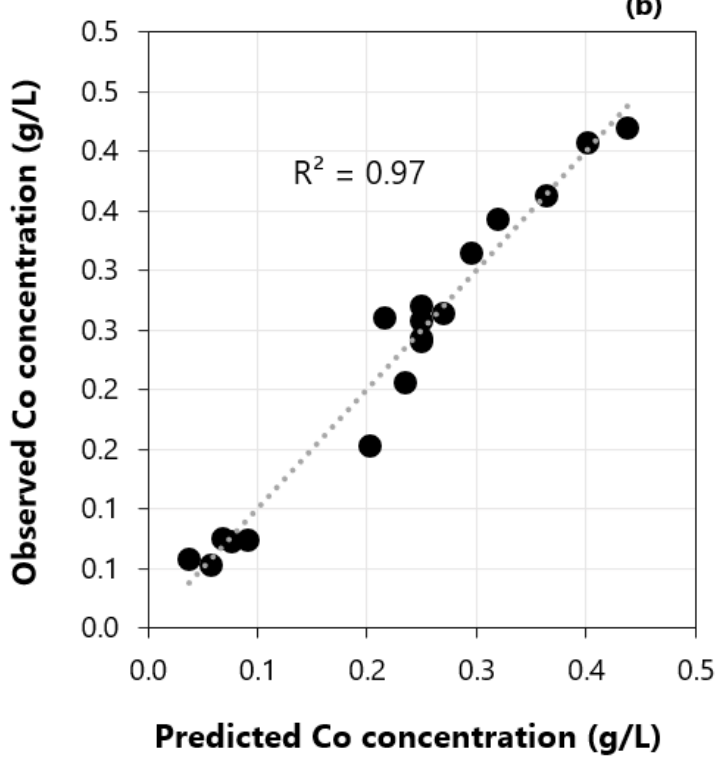

Figure 9. Responses predicted by the model versus experimentally observed: (a) manganese stripping and (b) cobalt stripping.

\subsection{Response Surfaces: Stripping of Manganese and Cobalt}

The contour plots in Figure 10a-c represent the response surfaces of the manganese stripping when the factor $x_{2}(\mathrm{O}: \mathrm{A}$ ratio) was set at its low level $(-1, \mathrm{O}: \mathrm{A}=1: 1)$, standard level (0, O:A = 4.5:1), and high level (+1, O:A = 8:1), respectively. The stripping of cobalt for different combinations of $\mathrm{O}: \mathrm{A}$ ratio and time is represented by the contour plots in Figure 10d, given that the concentration of sulfuric acid did not have a significant effect on it. The values of the response $(y)$ are represented by legends on the left side of each graph. Results are only valid in the range of values considered in this study. The concentrations of metals remaining in the organic phase and in the stripping product for each test are reported in the Supplementary Materials (Table S3).

When the O:A used in the stripping was 1:1 (Figure 10a), a low concentration of manganese was obtained and never exceeded $10 \mathrm{~g} / \mathrm{L}$, which was expected given the larger volume of aqueous phase. At the lowest concentration of $\mathrm{H}_{2} \mathrm{SO}_{4}(0.05 \mathrm{M})$, the lowest concentration of manganese in the stripping product was verified at the lowest stripping time (2 min), being lower than $3 \mathrm{~g} / \mathrm{L} \mathrm{Mn}$. With the increase in the concentration of $\mathrm{H}_{2} \mathrm{SO}_{4}$ and in the leaching time, a slight increase in the concentration of manganese was observed (maximum of $10 \mathrm{~g} / \mathrm{L}$ ).

The stripping behavior of manganese when the O:A ratio was set at 4.5:1 can be observed in Figure 10b. At this O:A ratio, the lowest concentration of manganese was around $8-10 \mathrm{~g} / \mathrm{L}$, and it was reached when the concentration of $\mathrm{H}_{2} \mathrm{SO}_{4}$ was the lowest $(0.05 \mathrm{M})$ at the shortest stripping time $(2 \mathrm{~min})$. Increasing the concentration of acid from 0.9 to $2 \mathrm{M}$ and the stripping time from 15 to 25 min promoted an increase in the concentration of manganese, which reached around $20 \mathrm{~g} / \mathrm{L}$.

The concentration of manganese was the highest when the O:A ratio was set at 8:1 (Figure 10c) and it was higher than $10 \mathrm{~g} / \mathrm{L}$ for all tested conditions. The concentration of 
manganese reached higher values when the other two variables (time and concentration of acid) were combined at the highest O:A ratio, which is related to the highly significant effect of the O:A ratio on the response, as previously discussed in the regression analysis. When the concentration of acid was at the lowest level $(0.05 \mathrm{M})$ and the stripping time was also at the lowest level $(2 \mathrm{~min})$, the concentration of manganese was around $10 \mathrm{~g} / \mathrm{L}$. When both factors were increased to their highest levels, the concentration of manganese achieved the maximum results (23-25 g/L). In Figure $10 \mathrm{a}-\mathrm{c}$, it is also possible to observe how the concentration of acid $\left(x_{1}\right)$ has a more pronounced effect on the concentration of manganese in the stripped product, which was also represented by a quadratic term in the model, causing a curvature in the response surface. Thus, a slight increase in the concentration of acid can cause a higher effect on the concentration of manganese.

The stripping of cobalt (Figure 10d) was mainly affected by the O:A ratio and by the leaching time, while the concentrations of $\mathrm{H}_{2} \mathrm{SO}_{4}$ tested in this study did not have a significant effect on the concentration of cobalt in the stripped liquor. The concentration of cobalt increased along with the O:A ratio and the stripping time, but it never exceeded $0.5 \mathrm{~g} / \mathrm{L}$. Thus, it can be concluded that very high concentrations of manganese in the stripping product $(>23 \mathrm{~g} / \mathrm{L})$ can be obtained using high $\mathrm{O}$ :A ratios and concentrations of sulfuric acid of around $1 \mathrm{M}$. However, the stripping time should not exceed around $13 \mathrm{~min}$, in order to keep the concentration of cobalt at a low level $(<0.3 \mathrm{~g} / \mathrm{L})$. Additionally, the fitted models can support the optimization of the stripping process.
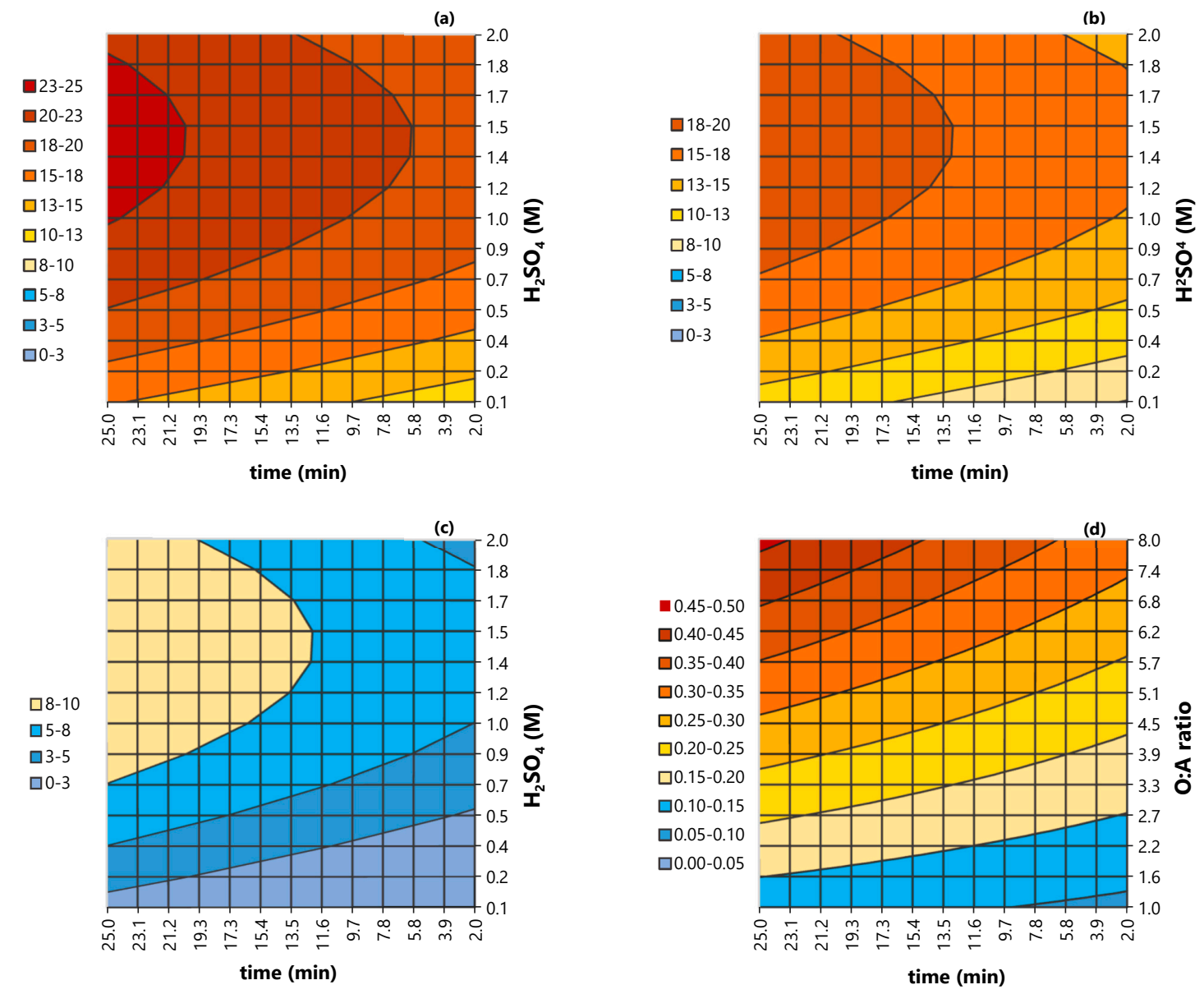

Figure 10. Contour plots representing the (a-c) stripping of manganese (a) when the O:A was set at 8:1, (b) when the O:A ratio was set at 4.5:1, and (c) when the O:A ratio was 1:1. (d) represents the stripping of cobalt at different combinations of stripping time and $\mathrm{O}: \mathrm{A}$ ratios. 
The fitted models can help to optimize the solvent extraction of manganese and can also assist with the construction of distribution isotherms and McCabe-Thiele diagrams, which are very helpful to predict the distribution of metals in both phases of the system (aqueous and organic) and to theoretically determine the number of required stages. The distribution isotherms for the stripping of manganese and cobalt, whose results were determined using the fitted models, are presented in the Supplementary Materials (Figure S1).

\section{Conclusions}

The recovery of manganese from a solution based on lithium-ion batteries was investigated using the factorial design of experiments and the response surface methodologies in order to assess the effect of different factors on the solvent extraction of manganese. These methodologies were also used to optimize the extraction and stripping stages, aiming to minimize the coextraction of cobalt. Preliminary tests were performed to determine the experimental conditions to be further investigated in the factorial design of experiments. The use of a modifier (TBP) was tested, but the formation of a third phase was not observed, and for this reason, additional tests with a modifier were not performed. The extraction of manganese using D2EHPA was fast, and maximum results were achieved after $10 \mathrm{~min}$ of contact time.

The factors evaluated in the extraction stage were the equilibrium $\mathrm{pH}$, the molar concentration of D2EHPA, and the organic to aqueous ratio. Under optimized conditions (O:A of 1.25:1, pH 3.25, and 0.5 M D2EHPA), extractions above $70 \% \mathrm{Mn}$ were reached in a single extraction stage with a coextraction of around only $5 \% \mathrm{Co}$, which was mostly removed in two scrubbing stages. Other combinations of factors can also result in high extractions of manganese and low coextractions of cobalt. In general, the coextraction of lithium and nickel remained low. The variables considered for the optimization of the stripping stage were the concentration of sulfuric acid, the organic to aqueous ratio, and the stripping time. A stripping product containing around $23 \mathrm{~g} / \mathrm{L} \mathrm{Mn}$ and around $0.3 \mathrm{~g} / \mathrm{L}$ Co can be obtained under optimized conditions (O:A of 8:1, $1 \mathrm{M} \mathrm{H}_{2} \mathrm{SO}_{4}$, and around $13 \mathrm{~min}$ of contact time) in a single stripping stage. Increasing the number of extraction stages can promote an increase in the concentration of manganese loaded in the organic phase and should be further investigated in up-scale tests using mixer-settlers. Moreover, the fitted models for the extraction and stripping stages can help optimize these processes and can also assist with the construction of McCabe-Thiele diagrams to predict the number of stages required to maximize the recovery of manganese.

The results obtained can support further investigations on the recovery of manganese from spent lithium-ion battery solutions, which are an important secondary resource of manganese, using solvent extraction with D2EHPA. Moreover, the use of methodologies to model and optimize the process can assist the process management, considering that multiple combinations of factors can result in high extractions of manganese and low coextractions of other metals. Knowing these alternatives can help to better design the process to reduce the consumption of energy and reagents, minimizing costs and environmental impacts.

Supplementary Materials: The following are available online at https: / www.mdpi.com/2075-4 $701 / 11 / 1 / 54 /$ s1,Table S1. Conditions of the experimental design and concentrations of metals in the raffinate and in the organic phase after one extraction stage. Contact time of $10 \mathrm{~min}$. Legend: [aq]: concentration of metal in aqueous phase, [org] concentration of meta in organic phase, Table S2. Conditions of the experimental design, distribution ratios $(D)$ and separation factors $(\beta)$ after one extraction stage. Contact time of $10 \mathrm{~min}$, Table S3. Conditions of the experimental design and concentrations of metals remaining in the organic phase and in the stripping product. Legend: [aq]: concentration of metal in aqueous; phase, [org] concentration of metal in organic phase, Figure S1. Distribution isotherms of (a) manganese stripping and (b) cobalt stripping obtained using the fitted models. Conditions used as input in the fitted models: stripping time: 13.5 min (coded variable: 0 ), O:A ratio: 8:1 (coded variable: +1 ), concentration of $\mathrm{H}_{2} \mathrm{SO}_{4}: 1 \mathrm{M}$ (coded variable: 0 ). 
Author Contributions: Data curation, formal analysis, investigation, visualization, writing-original draft preparation, N.V.; Conceptualization, methodology, validation, writing-review and editing, N.V., N.R., C.E., M.P.; resources, N.R., C.E., M.P.; project administration and supervision, M.P.; funding acquisition, C.E., M.P.; All authors have read and agreed to the published version of the manuscript.

Funding: This research was supported by VINNOVA (reference number of project: 2019-02069).

Institutional Review Board Statement: Not applicable.

Informed Consent Statement: Not applicable.

Data Availability Statement: The data presented in this study are available in supplementary material here.

Conflicts of Interest: The authors declare no conflict of interest.

\section{References}

1. The Royal Society of Chemistry, Manganese. Available online: https://www.rsc.org/periodic-table/element/25/manganese (accessed on 21 November 2020).

2. Corathers, L.A.; U.S. Geological Survey. Manganese. In Mineral Commodity Summaries; 2020; p. 105. Available online: https: //pubs.usgs.gov/periodicals/mcs2020/mcs2020.pdf (accessed on 10 October 2020).

3. South Australia, Government of South Australia, Department of Energy and Mining, Manganese. Available online: https: / / energymining.sa.gov.au/minerals/mineral_commodities/manganese (accessed on 21 November 2020).

4. Cardarelli, F. Materials Handbook: A Concise Desktop Reference, 2nd ed.; Springer: London, UK, 2008; ISBN 978-1-84628-668-1.

5. United States Government Printing Office. Strategic and Critical Materials. Hearings before a Subcommittee of the Committee on Military Affairs, United States Senate, Seventy-Seventh Congress, First Session, Relative to Strategic and Critical Materials and Minerals; Printed for the use of the Committee on Military Affairs, Washington: Fairfax, VA, USA, 1941.

6. Manganese Reserves and Resources of the World and Their Industrial Implications; National Academies Press: Washington, DC, USA, 1981; ISBN 978-0-309-32998-9.

7. Maynard, J.B. Manganese Rocks and Ores. In Isotope Geochemistry: The Origin and Formation of Manganese Rocks; Elsevier: Amsterdam, The Netherlands, 2017; ISBN 9780128031650.

8. Thackeray, M.M.; Croy, J.R.; Lee, E.; Gutierrez, A.; He, M.; Park, J.S.; Yonemoto, B.T.; Long, B.R.; Blauwkamp, J.D.; Johnson, C.S.; et al. The quest for manganese-rich electrodes for lithium batteries: Strategic design and electrochemical behavior. Sustain. Energy Fuels 2018, 2, 1375-1397. [CrossRef]

9. Olivetti, E.A.; Ceder, G.; Gaustad, G.G.; Fu, X. Lithium-Ion Battery Supply Chain Considerations: Analysis of Potential Bottlenecks in Critical Metals. Joule 2017, 1, 229-243. [CrossRef]

10. Cannon, W.F.; Kimball, B.E.; Corathers, L.A. Manganese; Schulz, K.J., DeYoung John, H., Jr., Seal, R.R., II, Bradley, D.C., Eds.; The U.S. Geological Survey: Reston, VA, USA, 2017; series number 1802; ISBN 978-1-4113-3991-0. Available online: https:/ / pubs.er.usgs.gov/publication/pp1802L (accessed on 21 November 2020).

11. Statista, Projected Size of the Global Lithium-Ion Battery Market from 2020 to 2025. Available online: https://www.statista.com/ statistics/1011187/projected-global-lithium-ion-battery-market-size/ (accessed on 21 November 2020).

12. Roskill Manganese Outlook to 2030, 16th ed. Available online: https://roskill.com/market-report/manganese/ (accessed on 25 November 2020).

13. Chow, N. Manganese ore for lithium batteries. Metal Powder Rep. 2012, 67, 34-36. [CrossRef]

14. Zhang, W.; Cheng, C.Y. Manganese metallurgy review. Part I: Leaching of ores/secondary materials and recovery of electrolytic/chemical manganese dioxide. Hydrometallurgy 2007, 89, 137-159. [CrossRef]

15. Biswal, A.; Chandra Tripathy, B.; Sanjay, K.; Subbaiah, T.; Minakshi, M. Electrolytic manganese dioxide (EMD): A perspective on worldwide production, reserves and its role in electrochemistry. RSC Adv. 2015, 5, 58255-58283. [CrossRef]

16. Moore Stephans. Manganese. Is It the Forgotten Battery Mineral? Snapshot Worldwide Manganese Ore Prices. Available online: https:/ / www.moorestephens.com.au/MediaLibsAndFiles/media/australia.moorestephens.com/Images/Profile\%20 Photos\%20(Contact\%20boxes)\%20110w\%20x\%20110h\%20px/Western\%20Australia/Manganese-Moore-Stephens-Report.pdf (accessed on 25 November 2020).

17. Jones, T.S. Manganese Recycling in the United States in 1998; US Department of the Interior, US Geological Survey: Reston, VA, USA, 2001. [CrossRef]

18. Bullis, L.H.; Mielke, J.E. Strategic and Critical Materials; Routledge: New York, NY, USA, 2019; ISBN 9780367288822.

19. Granata, G.; Pagnanelli, F.; Moscardini, E.; Takacova, Z.; Havlik, T.; Toro, L. Simultaneous recycling of nickel metal hydride, lithium ion and primary lithium batteries: Accomplishment of European Guidelines by optimizing mechanical pre-treatment and solvent extraction operations. J. Power Sources 2012, 212, 205-211. [CrossRef]

20. Peng, C.; Chang, C.; Wang, Z.; Wilson, B.P.; Liu, F.; Lundström, M. Recovery of High-Purity MnO2 from the Acid Leaching Solution of Spent Li-Ion Batteries. JOM 2020, 72, 790-799. [CrossRef] 
21. Yang, Y.; Xu, S.; He, Y. Lithium recycling and cathode material regeneration from acid leach liquor of spent lithium-ion battery via facile co-extraction and co-precipitation processes. Waste Manag. 2017, 64, 219-227. [CrossRef] [PubMed]

22. Wang, F.; Sun, R.; Xu, J.; Chen, Z.; Kang, M. Recovery of cobalt from spent lithium ion batteries using sulphuric acid leaching followed by solid-liquid separation and solvent extraction. RSC Adv. 2016, 6, 85303-85311. [CrossRef]

23. Joo, S.-H.; Shin, S.M.; Shin, D.; Oh, C.; Wang, J.-P. Extractive separation studies of manganese from spent lithium battery leachate using mixture of PC88A and Versatic 10 acid in kerosene. Hydrometallurgy 2015, 156, 136-141. [CrossRef]

24. Chen, X.; Chen, Y.; Zhou, T.; Liu, D.; Hu, H.; Fan, S. Hydrometallurgical recovery of metal values from sulfuric acid leaching liquor of spent lithium-ion batteries. Waste Manag. 2015, 38, 349-356. [CrossRef] [PubMed]

25. Pagnanelli, F.; Moscardini, E.; Altimari, P.; Abo Atia, T.; Toro, L. Cobalt products from real waste fractions of end of life lithium ion batteries. Waste Manag. 2016, 51, 214-221. [CrossRef] [PubMed]

26. Li, J.; Yang, X.; Yin, Z. Recovery of manganese from sulfuric acid leaching liquor of spent lithium-ion batteries and synthesis of lithium ion-sieve. J. Environ. Chem. Eng. 2018, 6, 6407-6413. [CrossRef]

27. Devi, N.B.; Nathsarma, K.C.; Chakravortty, V. Separation of divalent manganese and cobalt ions from sulphate solutions using sodium salts of D2EHPA, PC 88A and Cyanex 272. Hydrometallurgy 2000, 54, 117-131. [CrossRef]

28. Hossain, M.R.; Nash, S.; Rose, G.; Alam, S. Cobalt loaded D2EHPA for selective separation of manganese from cobalt electrolyte solution. Hydrometallurgy 2011, 107, 137-140. [CrossRef]

29. Cheng, C.Y. Purification of synthetic laterite leach solution by solvent extraction using D2EHPA. Hydrometallurgy 2000, 56, 369-386. [CrossRef]

30. Chen, X.; Zhou, T.; Kong, J.; Fang, H.; Chen, Y. Separation and recovery of metal values from leach liquor of waste lithium nickel cobalt manganese oxide based cathodes. Sep. Purif. Technol. 2015, 141, 76-83. [CrossRef]

31. Ahan, S.C.; Jeon, B.K.; Kim, B.E.; Lee, M.J.; Sonu, C.H. Method for Recovering Valuable Metals from Lithium Secondary Battery Wastes; 2010. Available online: https:/ / patents.google.com/patent/WO2012050317A3/en (accessed on 25 November 2020).

32. Jouni, P.; Erkki, P. Recovery of Manganese from Mixed Metal Solutions by Solvent Extraction with Organophosphorus Acid Extractants; Saint-Petersburg Mining University: St Petersburg, Russia, 2008.

33. Feather, A.; Sole, K.C.; Dreisinger, D.B. Pilot-plant evaluation of manganese removal and cobalt purification by solvent extraction. In Proceedings of the ISEC'99; Bercelona, Spain, 1999, Society of Chemical Industry (SCI): London, UK, 2001; Volume 2, ISBN 0-901001-83-8. Available online: http:/ / www.solventextract.org/documents/1999/ISEC-1999-Proceedings-Vol2.pdf (accessed on 25 November 2020).

34. Cole, P.M. The introduction of solvent-extraction steps during upgrading of a cobalt refinery. Hydrometallurgy 2002, 64, 69-77. [CrossRef]

35. Montgomery, D.C. Design and Analysis of Experiments, 8th ed; John Wiley \& Sons, Inc.: Hoboken, NJ, USA, 2012; ISBN 978-1-11814692-7.

36. Ritcey, G.M.; Ashbrook, A.W. Solvent Extraction: Principles and Applications to Process Metallurgy; Elsevier: Amsterdam, The Netherlands, 1984; ISBN 0444417702. 